\title{
Autologous lymphoma vaccines induce human T cell responses against multiple, unique epitopes
}

\author{
Sivasubramanian Baskar, ${ }^{1,2}$ Carol B. Kobrin, ${ }^{1}$ and Larry W. Kwak ${ }^{2}$
}

${ }^{1}$ Basic Research Program, SAIC-Frederick Inc., National Cancer Institute at Frederick, and ²Experimental Transplantation and Immunology Branch, Center for Cancer Research, NIH, Frederick, Maryland, USA.

\begin{abstract}
The clonotypic surface Ig receptor expressed by malignant B cells, idiotype, is a tumor-specific antigen and an attractive target for active immunotherapy. While Ab's specific for tumor idiotype have been well described in patients with $B$ cell malignancies, the precise antigenic epitopes in human idiotype recognized by autologous $T$ cells remain largely unknown. We report here that $T$ cell lines generated from lymphoma patients actively immunized with idiotype protein specifically recognized multiple, unique immunodominant epitopes in autologous tumor idiotype. Synthetic peptides corresponding to hypervariable, but not framework, regions of Ig heavy chain specifically stimulated $\mathrm{CD}^{+}$and $\mathrm{CD8}^{+} \mathrm{T}$ cells to proliferate and secrete proinflammatory cytokines in an MHC-associated manner. Detailed analysis revealed a minimal determinant of an immunodominant epitope, comprising critical residues at the amino terminus that may be a product of somatic hypermutation. Association of idiotype-specific $T$ cell responses with previously documented molecular remissions in idiotype-vaccinated patients suggests that the newly identified $T$ cell epitopes may be clinically relevant. Such antigenic epitopes may serve as candidates for novel peptide-vaccine strategies, and as tools to selectively expand tumor antigen-specific $T$ cells for adoptive immunotherapy and for monitoring $T$ cell immunity in vaccinated patients.
\end{abstract}

\section{Introduction}

Immune intervention in human cancers requires identification of tumor-specific or -associated antigens, and validation of their ability to elicit sufficient antitumor immune responses in patients. Mutated and unmutated self-proteins as well as non-self-proteins may be useful target antigens in some human cancers (1-3). In B cell malignancies, the clonotypic surface Ig expressed by malignant B cells, idiotype (Id), is a tumor-specific antigen (4-6) and, therefore, provides a unique opportunity to target the antitumor immune responses. Gene rearrangements that occur during variable, diversity, and joining region (VDJ) and variable and joining region (VJ) recombination of Ig heavy and light chains and during the somatic hypermutation that is prevalent in mature normal and malignant B cells, including follicular lymphoma (FL), further increased the probability of the generation of unique epitopes that can provide tumor-specific target antigens (7-12).

The earliest human studies showed that immunization with Id conjugated to an immunogenic carrier, keyhole limpet hemocyanin (KLH), induced anti-Id Ab responses (13). More recent studies have focused on the induction of cellular immunity against malignant B cells using different vaccination strategies. Vaccination with Id protein has been shown to elicit both $\mathrm{CD}^{+}$ and $\mathrm{CD}^{+} \mathrm{T}$ cell responses (14-18), suggesting the presence of antigenic epitopes in Id that can stably associate with MHC class

Nonstandard abbreviations used: complementarity-determining region (CDR); follicular lymphoma (FL); framework region (FWR); idiotype (Id); joining region of Ig heavy chain (JH); keyhole limpet hemocyanin (KLH); phycoerythrin (PE); T cell receptor (TCR); variable, diversity, and joining regions of Ig (VDJ); variable and joining regions of $\operatorname{Ig}(\mathrm{VJ})$; variable region of $\operatorname{Ig}$ heavy chain $\left(\operatorname{Ig} \mathrm{V}_{\mathrm{H}}\right)$.

Conflict of interest: The authors have declared that no conflict of interest exists.

Citation for this article: J. Clin. Invest. 113:1498-1510 (2004).

doi:10.1172/JCI200420312.
I and class II molecules. Previous studies have shown that T cells from patients with B cell malignancies can be stimulated in vitro with synthetic peptides derived from complementarity-determining regions (CDRs) that form the hypervariable segments of Ig heavy chain, Ig $\mathrm{V}_{\mathrm{H}}$ (19-24). Nonetheless, the precise nature of antigenic epitopes recognized by the responding $\mathrm{T}$ cells in vivo is incompletely characterized (25-27).

In this study, we have generated Id-specific $\mathrm{T}$ cell lines from postvaccine PBMCs of FL patients who had been actively immunized with a vaccine formulation that successfully induced $\mathrm{CD}^{+}$ and $\mathrm{CD}^{+} \mathrm{T}$ cell responses and molecular remissions (17), and used them as tools to identify functional $\mathrm{T}$ cell epitopes. Multiple, unique antigenic peptides were characterized that induced specific proliferation and secretion of proinflammatory cytokines in an MHC-associated fashion. Such defined antigenic epitopes may serve as candidates for novel peptide-vaccine strategies, as tools to selectively expand tumor antigen-specific $\mathrm{T}$ cells for adoptive immunotherapy, and as reagents for immune monitoring of vaccinated patients.

\section{Methods}

Patients, vaccine, and PBMC samples. Patients with advanced FL enrolled on this institutional review board-approved vaccine study were described previously (17). Briefly, patients had received chemotherapy to the first complete remission. Following at least 6 months of immune recovery, they received five subcutaneous injections of autologous, tumor-derived Ig protein conjugated to KLH (Id-KLH), mixed with human recombinant GM-CSF (rGM$\mathrm{CSF}$ ). While for FL patients the Id was isolated from heterohybridomas generated by fusion with tumor B cells, for myeloma patients the Id was isolated from patients' serum by affinity chromatography (17). Blood samples were collected from the patients 
Table 1

HLA alleles expressed by the patients and cell lines used in the study

\begin{tabular}{|c|c|c|c|c|c|c|}
\hline \multirow[t]{2}{*}{ Patient/Cell line } & \multicolumn{3}{|c|}{ HLA class I } & \multicolumn{3}{|c|}{ HLA class II } \\
\hline & A & B & $\mathrm{Cw}$ & DRB1 & DQB1 & DRB \\
\hline LE & 02,26 & 07,13 & 06,07 & 0701,1501 & 0201,0602 & $4^{\star} 01,5^{\star} 0101$ \\
\hline TL & 02,29 & 44,51 & $01,-A$ & 0701,1401 & 0201,0503 & $3 * 0202,4^{\star} 01$ \\
\hline BS & 01,0201 & 08,51 & 07,15 & 03,13 & 02,06 & $3^{\star} 01,3^{\star} 02$ \\
\hline$B L$ & 01,11 & 08,44 & 05,0701 & 03,12 & 02,03 & $3^{\star} 01,3^{\star} 02$ \\
\hline VS & $02,-$ & 07,57 & 06,07 & 07,15 & 03,06 & $4^{\star} 01,5^{\star} 01$ \\
\hline HR & 03,28 & 14,35 & $04,-$ & 0301,0303 & 0201,0301 & $3^{\star} 0101,3^{\star} 02$ \\
\hline BE & 02,28 & 44,62 & 03,05 & 0102,1301 & 0501,0604 & $3^{\star} 0604,-$ \\
\hline RB & 02,68 & $27,-$ & $02,-$ & 0101,1601 & 0501,05 & $5^{\star} 0202,-$ \\
\hline$S G$ & 24,30 & 13,14 & 06,08 & 0701,1302 & $N D^{B}$ & $3^{\star} 00^{\complement}, 4^{\star} 01$ \\
\hline NC & 02,24 & 08,15 & 07,12 & 0301,1101 & 0201,0603 & $3^{*} 0101,3^{*} 0202$ \\
\hline$J R$ & 29,32 & $44,-$ & $05,-$ & 07,12 & 03,03 & $3^{\star} 02,4^{\star} 01$ \\
\hline LK & 01,03 & $07,-$ & $07,-$ & $15,-$ & $06,-$ & $5^{\star} 01,-$ \\
\hline $\mathrm{MC}$ & 01,03 & 07,08 & 07,- & 0901,1501 & ND & $4^{\star} 01,5^{\star} 00$ \\
\hline EBV-583 & 03,3101 & 07,44 & 0501,0702 & 04,1501 & 03,06 & $4^{\star} 01,5^{\star} 01$ \\
\hline EBV-1087 & 02,35 & 13,35 & 0401,0602 & 07,12 & 02,03 & $3^{\star} 02,4^{\star} 01$ \\
\hline EBV-1088 & 01,02 & 08,44 & 0501,07 & 0301,04 & 02,03 & $3^{\star} 01,4^{\star} 01$ \\
\hline EBV-1363 & 01,02 & 44,51 & 01,0501 & 01,- & $05,-$ & Not present \\
\hline
\end{tabular}

${ }^{A} A$ dash indicates that the second allele was not amplified in the reaction or was

homozygous. BND, not determined. ${ }^{\mathrm{C}} \mathrm{A}$ specific allele could not be assigned. tumor cells, and corresponding $\mathrm{T}$ cell lines were established by repeated stimulation with irradiated autologous tumor cells as described above. $\mathrm{T}$ cells were generally used between 10 and 15 days after previous Id or tumor stimulation.

Epitope-prediction analysis and peptide synthesis. DNA sequence of FL patients' tumor $\operatorname{Ig} \mathrm{V}_{\mathrm{H}}$ was obtained by PCR-based fingerprinting of tumor biopsy samples as described previously (29). The amino acid sequences deduced from the coding DNA sequences were analyzed by epitope-prediction programs (30-32). Candidate peptides representing the framework region (FWR), $\mathrm{CDR}$, and joining region $(\mathrm{JH})$ of tumor $\operatorname{Ig} \mathrm{V}_{\mathrm{H}}$ predicted to bind the HLA allele(s) of a corresponding patient were selected. Some of the peptides contained residue(s) overlapping into the adjacent region. Peptides were synthesized by f-moc methodology and were shown to be more than 95\% pure using matrix-assisted laser disorption/ionization-time of flight mass spectrometry with an $\alpha$ matrix and a C-18 analytical HPLC column (Macromolecular Resources, Colorado State University, Fort Collins, Colorado, USA). Peptides were dissolved in 5-10 $\mu \mathrm{l}$ of before and after vaccine administration. PBMCs were prepared by density gradient separation (lymphocyte separation medium; ICN Biomedicals Inc., Aurora, Ohio, USA) and cryopreserved in liquid nitrogen until use. The HLA typing was done at the National Institutes of Health HLA laboratory, and the HLA class I and class II alleles expressed by the patients and cell lines used in the study are presented in Table 1.

Generation of antigen-specific T cell lines. The culture medium RPMI 1640 containing GlutaMax (Life Technologies Inc., Gaithersburg, Maryland, USA) was supplemented with $100 \mu \mathrm{g} / \mathrm{ml}$ streptomycin sulphate, $100 \mathrm{U} / \mathrm{ml}$ penicillin, $10 \mu \mathrm{g} / \mathrm{ml}$ gentamicin sulfate (BioWhittaker Inc., Walkersville, Maryland, USA), 20 mM HEPES, 1 $\mathrm{mM}$ sodium pyruvate (Life Technologies Inc., $5 \%$ heat-inactivated human serum from $\mathrm{AB}^{+}$individuals (Gemini BioProducts, Woodland, California, USA), and $50 \mu \mathrm{M} 2$-mercaptoethanol (2-ME; Sigma-Aldrich, St. Louis, Missouri, USA). All components were mixed and sterilized using a $0.2-\mu \mathrm{m}$ filter (Whatman Inc., Clifton, New Jersey, USA). Antigen-specific T cell lines were generated by repeated stimulation and rest cycles, as described previously (28). Briefly, postvaccine PBMCs (about $20 \times 10^{6}$ ) were first stimulated in vitro with autologous Id protein $(100 \mu \mathrm{g} / \mathrm{ml})$, and during subsequent restimulations, $5 \times 10^{5} \mathrm{~T}$ cells were cultured with $2.5 \times 10^{6}$ to $3.0 \times 10^{6}$ irradiated $(3.3 \mathrm{~Gy}$ ) autologous prevaccine PBMCs as APCs and autologous Id. After 5-7 cycles of stimulation and rest, Id-specific T cell lines were established. During subsequent stimulations, $25 \mathrm{U} / \mathrm{ml}$ human recombinant IL-2 (rIL-2) (National Cancer Institute Biological Research Branch Pre-clinical Repository, Frederick, Maryland, USA) and 5 ng/ml rIL-7 (PeproTech Inc., Rocky Hill, New Jersey, USA) were added 1-2 days after antigen stimulation and every 2-3 days thereafter to expand the Id-specific $\mathrm{T}$ cells. Alternatively (e.g., patient BL), the postvaccine PBMCs were enriched for $\mathrm{CD}^{+}$or $\mathrm{CD}^{+}$populations by magnetic separation using anti-CD8 or anti-CD4 microbeads, respectively (Miltenyi Biotec Inc., Auburn, California, USA). Initially, $10 \times 10^{6} \mathrm{CD}^{+}$or $\mathrm{CD}^{+}$ $\mathrm{T}$ cells were cultured with $30 \times 10^{6}$ irradiated $(2.4 \mathrm{~Gy})$ autologous
DMSO when necessary, and stock solutions $(1 \mathrm{mM})$ were prepared in PBS, filtered, and stored at $-70^{\circ} \mathrm{C}$ until use.

$A b$ reagents and flow cytometry. Phenotypic characterization of $\mathrm{T}$ cells was performed by multiparameter flow cytometry in FACSCalibur (Becton Dickinson Immunocytometry Systems, San Jose, California, USA) using the following fluorochrome-conjugated mAb's: Simultest reagents: G1/G2a, CD3/CD4, CD3/CD8, CD3/CD19, CD3/CD16+56, CD45/CD14, CD3/HLA-DR; single-color reagents: CD3-allophycocyanin (CD3-APC), CD4-APC, CD25-FITC, CD45RA-phycoerythrin (CD45RA-PE), CD45ROPE, CD69-APC, CD45-FITC, and CD45-PE (BD Biosciences Immunocytometry Systems, San Jose, California, USA), and HLA-A,B,C-PE, HLA-DR,DP,DQ-FITC, $\alpha \beta$ T cell receptor-FITC (TCR $\alpha \beta$-FITC), TCR $\gamma \delta$-FITC, and isotype control Ab (BD Biosciences PharMingen, San Diego, California, USA). A total of 20,000 gated events were collected for each sample in a list-mode file, and data analysis was performed using CellQuest software (BD Biosciences Immunocytometry Systems).

For inhibition studies, we used mAb's against HLA-DR; HLADP; HLA-DQ; HLA-A, -B, and -C (class I); or HLA-DP, -DQ, and -DR (class II); and isotype controls IgG1k or IgG2ak (PharMingen International), HLA-DR52, and HLA-B*08 (both from One Lambda Inc., Canoga Park, California, USA). All mAb's were dialyzed before use. The APCs were incubated with anti-HLA Ab or isotype control $\operatorname{Ig}(25 \mu \mathrm{g} / \mathrm{ml})$ for $2-3$ hours prior to the addition of T cells. The percentage inhibition was calculated based on the responses in the absence of $\mathrm{Ab}$ in each group.

Antigen-specific proliferation and cytokine production. Postvaccine PBMCs $\left(6 \times 10^{5}\right)$, collected about 1 month after the last vaccine, were cultured in the absence or presence of the indicated amount of antigen. When $\mathrm{T}$ cell lines were used, $1 \times 10^{5} \mathrm{~T}$ cells were cultured with $6 \times 10^{5}$ irradiated $(3.3 \mathrm{~Gy})$ autologous prevaccine PBMCs or $3 \times 10^{5}$ irradiated (120 Gy) partially HLA-matched, Epstein-Barr virus-transformed (EBV) cell lines (33) in the absence or presence of the indicated Id protein/peptide. The proliferation 


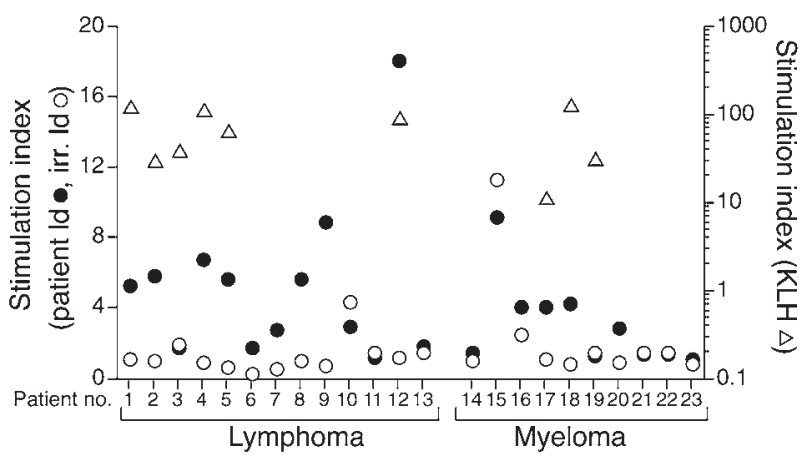

Figure 1

Postvaccine PBMCs specifically responded to autologous Id. PBMCs from Id-KLH-vaccinated patients were cultured in the absence or presence of $100 \mu \mathrm{g} / \mathrm{ml}$ autologous Id, isotype-matched irrelevant (irr.) Id, or $\mathrm{KLH}$. The proliferation responses (cpm) to autologous Id (filled circles) and irrelevant Id (open circles) are depicted on the left ordinate, and the responses to $\mathrm{KLH}$ (open triangles) on the right ordinate. The numbers of the FL and myeloma patients studied are indicated on the abscissa.

response was measured by $\left[{ }^{3} \mathrm{H}\right]$ thymidine incorporation (28). All cultures were set up in triplicate, and the arithmetic mean cpm was calculated. The SD from the arithmetic mean values was less than $10 \%$ in all the experiments. The change in cpm was calculated by subtraction of mean cpm in the absence of antigen from mean cpm in the presence of antigen.

For determination of cytokine responses in ex vivo PBMCs, $2 \times 10^{6}$ to $3 \times 10^{6}$ prevaccine or postvaccine PBMCs were cultured in 48-well plates in the absence or presence of $100 \mu \mathrm{M}$ of the indicated peptide. Three and six days later, cell-free culture supernatants were collected and stored frozen at $-70^{\circ} \mathrm{C}$ until analysis. Cytokine ELISA was performed using a Quantikine kit for GM-CSF, IFN- $\gamma$, and TNF- $\alpha$ (R\&D Systems Inc., Minneapolis, Minnesota, USA) according to the manufacturer's direction. To determine the cytokine responses by $\mathrm{T}$ cell lines, $5 \times 10^{5} \mathrm{~T}$ cells, and $2 \times 10^{6}$ to $3 \times 10^{6}$ irradiated autologous PBMCs or HLA-matched or -unmatched APCs were cultured in the absence or presence of the indicated antigen. The antitumor responses by $\mathrm{T}$ cell lines from patient BL were determined by culturing of $5 \times 10^{5}$ T cells with $2 \times 10^{6}$ to $3 \times 10^{6}$ irradiated autologous or heterologous tumor cells, and corresponding PBMCs were used as controls. Cell-free supernatants were collected 3 and 6 days later, and the cytokines secreted were determined. The sensitivity of this assay for all the cytokines was $7.8 \mathrm{pg} / \mathrm{ml}$, and the values were less than 7.8 , less than 15.6 , or less than $31.2 \mathrm{pg} / \mathrm{ml}$ depending on the initial dilution of the samples.

Intracellular cytokine assay. The frequency of antigen-specific $\mathrm{T}$ cells was determined by intracellular cytokine staining. T cells $\left(5 \times 10^{5}\right)$ were cultured with $2 \times 10^{6}$ to $3 \times 10^{6}$ irradiated autologous CD3-depleted PBMCs or partially HLA-matched EBV-583 cells (two class I and four class II alleles matched with the patient LE; Table 1) as APCs in 48-well plates in the absence or presence of the indicated antigen and $5 \mu \mathrm{g} / \mathrm{ml}$ anti-CD28 Ab (PharMingen International). Two hours after antigen stimulation, $1 \mu \mathrm{M}$ monensin and $5 \mu \mathrm{g} / \mathrm{ml}$ brefeldin-A (Sigma-Aldrich) were added to block cytokine secretion. Following overnight culture, the cells were harvested and processed for intracellular cytokine staining as described previously (34). The potentially responding $\mathrm{T}$ cells were identified first by gating on lymphocytes (forward scatter), and then by fluorescence gating (surface staining with CD3-FITC, CD4-peridinin chlorophyll protein [CD4-PerCP], and CD69APC). For intracellular staining, the following anti-cytokine Ab's were used: IFN- $\gamma-\mathrm{PE}$, TNF- $\alpha-\mathrm{PE}$, IL-4-PE, IL-10-PE, and isotype controls IgG1-PE and IgG2a-PE (BD Biosciences). Flow cytometry was done as described above.

\section{Results}

Postvaccine PBMCs respond specifically to autologous Id protein. The goal of this study was to generate human $\mathrm{T}$ cell lines that can recognize autologous tumor Id and/or autologous tumor cells, and to delineate immunodominant epitopes in $\mathrm{Ig} \mathrm{V}_{\mathrm{H}}$. As a prologue, postvaccine PBMCs from 23 patients were cultured in vitro in the absence or presence of autologous Id or isotypematched Id from unrelated patients (17). About 69\% (9 of 13) of FL patients showed a specific proliferation response (stimulation index $\geq 3$ ) to the self-tumor antigen, autologous Id (Figure 1). By contrast, only $20 \%$ (two of ten) of myeloma patients showed specific, albeit weaker, responses to autologous Id. Nevertheless, all patients tested showed vigorous $\mathrm{T}$ cell proliferation responses to the foreign carrier protein, KLH, which demonstrated the immunocompetence of the patients at the time of vaccine administration. These results extend our previous observation that autologous tumor-specific cytokine responses were elicited by Id-KLH vaccine (17). All four FL patients who did not respond to Id protein harbored peptide motifs in their Id sequences that were predicted to bind to one or more HLA alleles expressed by these patients (data not shown). Some of the FL patients that showed specific response to autologous Id were chosen for further studies described below.

$T$ cell lines respond to autologous Id protein and/or autologous tumor. Two different strategies were used to generate $\mathrm{T}$ cell lines from vaccinated patients. Postvaccine PBMCs from four FL patients were repeatedly stimulated with either autologous Id protein or autologous tumor cells (see Methods). Id-raised and tumor-raised $\mathrm{T}$ cell lines from patient LE (LE-1 and LE-2, respectively) consisted of mostly (>98\%) $\mathrm{CD}^{+} \mathrm{CD}^{+} \mathrm{T}$ cells (Table 2 ). Prolonged culturing and repeated in vitro stimulations with Id protein probably provided selective growth advantage to $\mathrm{CD}^{+} \mathrm{T}$ cells, and eventually these lines consisted of $100 \% \mathrm{CD}^{+} \mathrm{T}$ cells. Id-raised and tumor-raised $\mathrm{T}$

\section{Table 2}

T cell lines used in this study

\begin{tabular}{lcccc} 
Patient & T cell lines & In vitro stimulations & \multicolumn{2}{c}{ Phenotype $^{\mathbf{B}}$} \\
\multirow{2}{*}{$\mathrm{LE}$} & & & CD4 & CD8 \\
& LE-1 & Id & 98 & 2 \\
$\mathrm{TL}$ & $\mathrm{LE}-2$ & Tumor & 99 & 0.2 \\
& $\mathrm{TL}-1$ & Id & 82 & 18 \\
$\mathrm{BS}$ & $\mathrm{TL}-2$ & Tumor & 92 & 8 \\
& $\mathrm{BS}-1$ & Id & 77 & 23 \\
$\mathrm{BL}$ & $\mathrm{BS}-2$ & Id & 85 & 14 \\
& $\mathrm{BL}-1$ & Tumor & 99 & 0.4 \\
& $\mathrm{BL}-2$ & Tumor & 94 & 1.6 \\
& $\mathrm{BL}-3$ & Tumor & 0.3 & 99 \\
& $\mathrm{BL}-4$ & Tumor & 0.6 & 99
\end{tabular}

AThe T cell lines were generated by repeated in vitro stimulations of postvaccine PBMCs with autologous Id protein or irradiated autologous tumor. ${ }^{\mathrm{B} T h e}$ percentages of $\mathrm{CD}^{+}$and $\mathrm{CD} 8^{+} \mathrm{T}$ cell subsets are shown. 
A

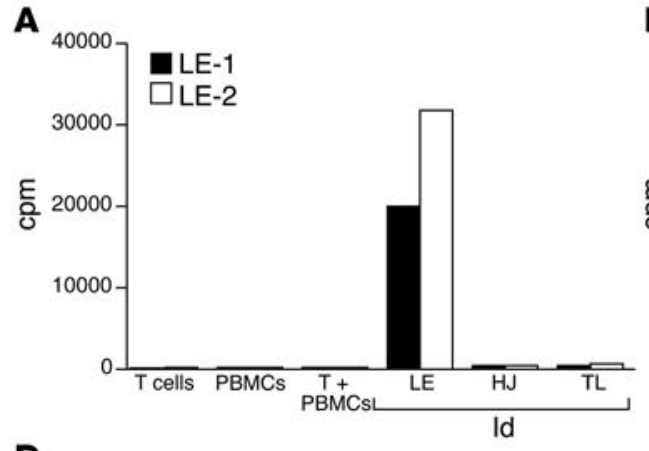

D

D

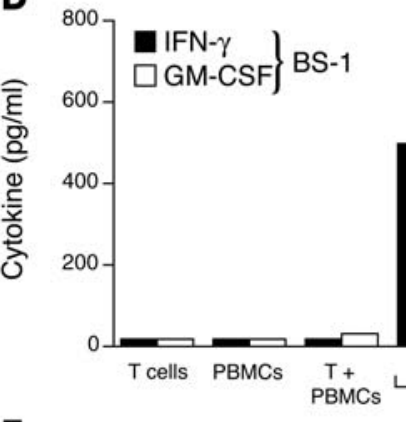

B

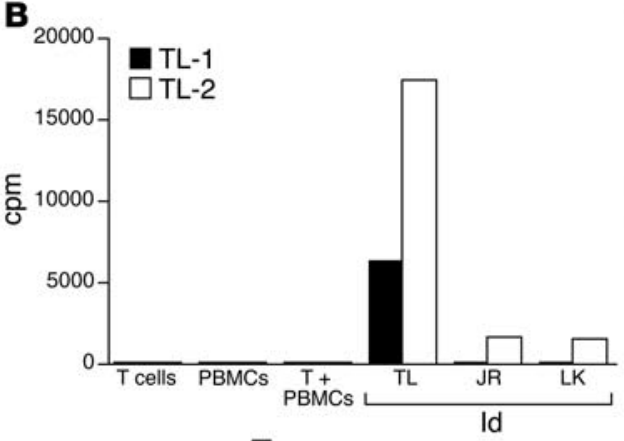

E.
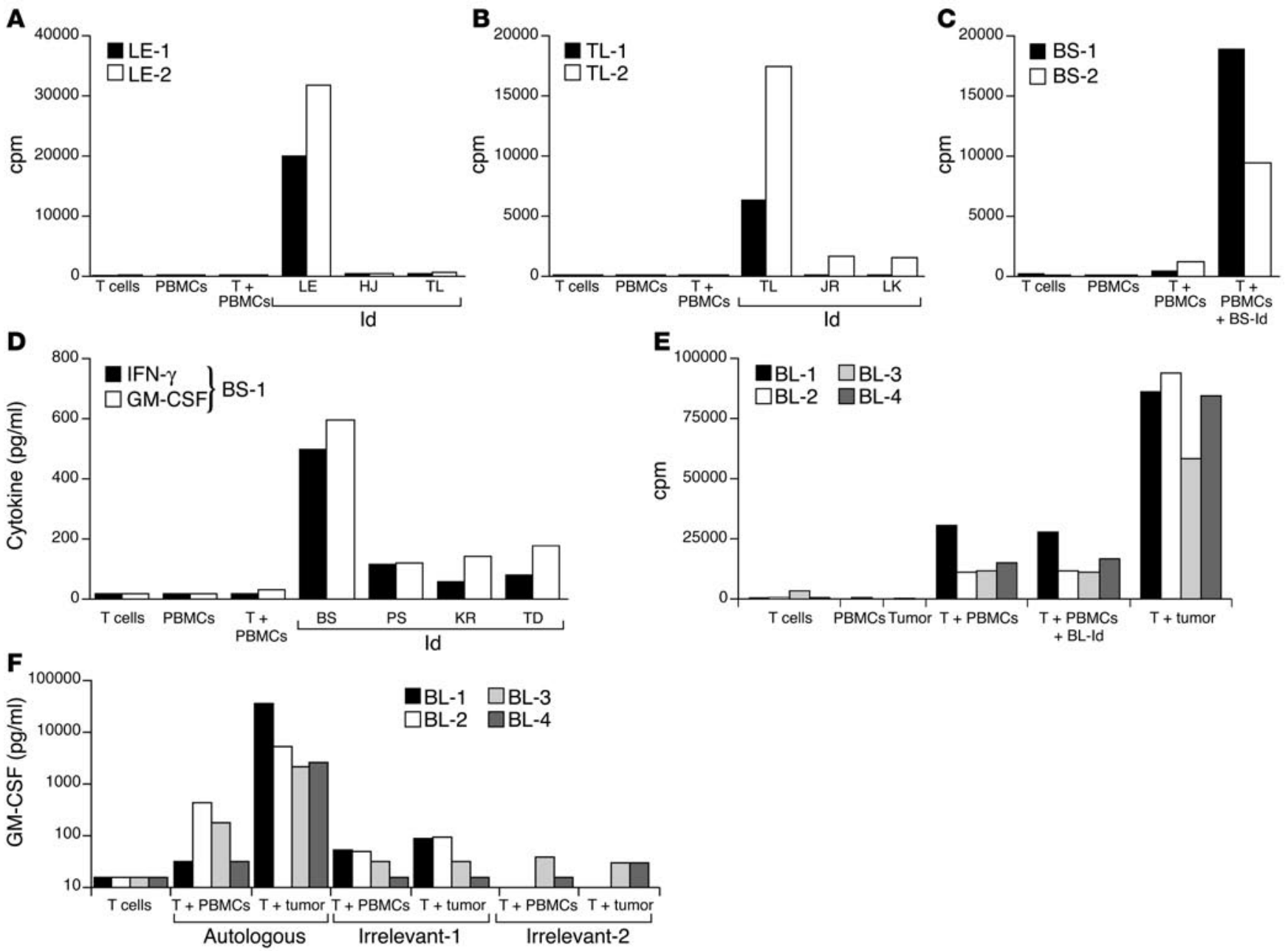

Figure 2

T cell lines derived from vaccinated FL patients specifically responded to autologous Id or tumor. (A-C) T cells from patients LE, TL, and BS were cultured with irradiated autologous PBMCs in the absence or presence of $100 \mu \mathrm{g} / \mathrm{ml}$ autologous Id or irrelevant ld from other patients as indicated. A, B, and $\mathbf{C}$ show the proliferation responses (cpm) by T cell lines from patients LE, TL, and BS, respectively. (D) BS-1 T cells were cultured with irradiated autologous PBMCs in the absence or presence of indicated Id, and cytokine responses were measured. (E) Proliferation response by BL T cells cultured with irradiated autologous PBMCs in the absence or presence of Id. In addition, BL T cells were cultured with irradiated autologous tumor cells. (F) Cytokine response by BL T cells cultured either with irradiated autologous (BL) PBMCs or tumor cells, or with PBMCs or tumor cells from irrelevant patients (LK or MC). When PBMCs or tumor cells from patients BL, LK, or MC were cultured alone, they secreted only background levels of cytokines. Results from a representative experiment are shown.

cell lines from patient TL (TL-1 and TL-2, respectively) and patient BS (BS-1 and BS-2, respectively) consisted of $77-92 \% \mathrm{CD}^{+} \mathrm{CD}^{+}$ and $8-23 \% \mathrm{CD}^{+}{ }^{+} \mathrm{CD}^{+} \mathrm{T}$ cells. Postvaccine PBMCs from patient $\mathrm{BL}$ were repeatedly stimulated with autologous tumor to establish $\mathrm{CD}^{+}$(BL-1 and BL-2) and CD8 ${ }^{+}$(BL-3 and BL-4) T cell lines. Further characterization revealed that all the Id- and tumor-reactive $T$ cells expressed TCR $\alpha \beta$, and activation markers such as HLA-DR, CD25, CD45RO, and CD69 (data not shown), consistent with an antigen-experienced memory phenotype. There was no significant staining with $\mathrm{Ab}$ to TCR $\gamma \delta, \mathrm{CD} 16 / 56$, CD14, or CD19 (data not shown). Similar attempts to generate Id-specific $\mathrm{T}$ cell lines from prevaccine PBMCs were unsuccessful.

$\mathrm{T}$ cell lines generated from patient LE (LE-1 and LE-2) showed significant proliferation responses to autologous Id (Figure 2A), but not to isotype-matched Id proteins from other patients $(\mathrm{HJ}$ and TL). Similarly, T cell lines generated from patients TL and BS (TL-1,
TL-2, BS-1, and BS-2) also showed corresponding Id-specific proliferation (Figure 2, B and C). In the case of BS T cells, the antigen-specific response was shown by cytokine secretion (Figure 2D). Again, irrelevant Id proteins from other patients (JR and LK were controls for TL, and PS, KR, and TD were controls for BS) failed to induce significant responses. In addition, Id-specific cytokine responses by $\mathrm{LE}$ and TL T cell lines paralleled their proliferation responses (data not shown). Furthermore, two $\mathrm{CD} 4^{+} \mathrm{T}$ cell lines (BL-1 and $\mathrm{BL}-2$ ) and two $\mathrm{CD}^{+} \mathrm{T}$ cell lines (BL-3 and BL-4) from patient $\mathrm{BL}$ exhibited significant responses to autologous tumor, but not to autologous Id (Figure 2E). The specificity of antitumor response was demonstrated by the absence of response to tumors from other patients, LK and MC (Figure 2F). No significant response to alloantigens was observed.

Collectively, these results demonstrate that the Id-raised $\mathrm{T}$ cell lines generated from postvaccine PBMCs of FL patients specifi- 
Table 3

Synthetic peptides used in this study

\begin{tabular}{|c|c|c|}
\hline Patient & Synthetic peptides ${ }^{A}$ & Ig $V_{H}$ position ${ }^{B}$ \\
\hline \multirow[t]{17}{*}{ LE } & YITNTSSYISYADSVKG & CDR2-1 \\
\hline & ITNTSSYISYADSVK & CDR2-2 \\
\hline & TNTSSYISYADSVK & CDR2-3 \\
\hline & NTSSYISYADSVK & CDR2-4 \\
\hline & TSSYISYADSVK & CDR2-5 \\
\hline & SSYISYADSVK & CDR2-6 \\
\hline & YITNTSSYISYADSV & CDR2-7 \\
\hline & YITNTSSYISYADS & CDR2-8 \\
\hline & YITNTSSYISYAD & CDR2-9 \\
\hline & YITNTSSYISYA & CDR2-10 \\
\hline & YITNTSSYISY & CDR2-11 \\
\hline & TNTSSYISYAD & CDR2-12 \\
\hline & HNRSAVRAPASEIHFHLDV & CDR3 \\
\hline & VKGRFTVSRDNAKNS & CDR2/FWR3 \\
\hline & NSMFLQMNSLRVEDT & FWR3 \\
\hline & TAIYYCVRHNRSAVR & FWR3/CDR3 \\
\hline & HLDVWGQGTTVTVSS & $\mathrm{CDR3/JH}$ \\
\hline \multirow[t]{12}{*}{$\mathrm{TL}$} & FANNWIHWV & CDR1 \\
\hline & VPGKGLVWV & FWR2 \\
\hline & LNGDGKIANYTDSVKGRFTI & CDR2 \\
\hline & TVFLQMNSL & FWR3-1 \\
\hline & FLQMNSLRV & FWR3-2 \\
\hline & ATTTGGGLNFGLDVW & CDR3-1 \\
\hline & TTGGGLNFGLDV & CDR3-2 \\
\hline & GGGLNFGLDV & CDR3-3 \\
\hline & GGLNFGLDV & CDR3-4 \\
\hline & CATTTGGGL & CDR3-5 \\
\hline & ALYYCATTT & CDR3-6 \\
\hline & WGHGTAVNV & JH \\
\hline \multirow[t]{15}{*}{ BS } & ANITQEGSQKNYVDS & CDR2-1 \\
\hline & ITQEGSQKN & CDR2-2 \\
\hline & TQEGSQKNY & CDR2-3 \\
\hline & QEGSQKNYV & CDR2-4 \\
\hline & SQKNYVDSV & CDR2-5 \\
\hline & RFTISRDNAKNIVFL & FWR3-1 \\
\hline & LQMSSLRVEDTALYY & FWR3-2 \\
\hline & FLQMSSLRV & FWR3-3 \\
\hline & RVEDTALYY & FWR3-4 \\
\hline & ARHNDDTSV & CDR3-1 \\
\hline & NDDTSVTFD & CDR3-2 \\
\hline & DDTSVTFDY & CDR3-3 \\
\hline & CARHNDDTSVTFDYW & CDR3-4 \\
\hline & RHNDDTSVTFDYWGQ & CDR3-5 \\
\hline & DTSVTFDYWGQGTLV & CDR3-6 \\
\hline \multirow[t]{12}{*}{$\mathrm{BL}$} & ISQSGSDTSYVDSVK & CDR2-1 \\
\hline & GSDTSYVDS & CDR2-2 \\
\hline & DTSYVDSVKGRFTIS & CDR2-3 \\
\hline & YVDSVKGRF & CDR2-4 \\
\hline & SQSGSDTSY & CDR2-5 \\
\hline & RFTISRDNAQKSLFL & FWR3-1 \\
\hline & NSLRVEDTAIYYCTG & FWR3-2 \\
\hline & DTAIYYCTGGDDWSG & FWR3-3 \\
\hline & YYCTGGDDWSGYFKF & FWR3-4 \\
\hline & LRVEDTAIY & FWR3-5 \\
\hline & TGGDDWSGY & CDR3-1 \\
\hline & GDDWSGYFK & CDR3-2 \\
\hline
\end{tabular}

ASingle-letter code for the amino acids is used. BThe CDR and FWR amino acid sequences are numbered according to Kabat et al. (see ref. 49). cally recognized autologous Id protein and/or autologous tumor, and they were used to determine the precise antigenic epitope(s) recognized in the studies described below.

$T$ cell epitopes are predominantly localized in the CDRs of tumor Ig $V_{H}$. To elucidate the precise nature of antigenic epitopes recognized by Id-specific $T$ cells, synthetic peptides were made from amino acid sequences deduced from nucleotide sequences of individual patients' tumor $\mathrm{Ig} \mathrm{V}_{\mathrm{H}}$ region. At first, we made synthetic peptides corresponding to the entire CDR2 and CDR3 segments of tumor $\operatorname{Ig} V_{\mathrm{H}}$. Next, using bioinformatics, we identified candidate peptides that were predicted to bind HLA alleles of a corresponding patient $(30,31)$ and synthesized peptides representing different $I g V_{H}$ regions for each of the four patients studied (Table 3 ). For patients LE and TL, additional peptides were made by single-amino acid truncations at the $\mathrm{NH}_{2}$ and/or COOH termini of the CDR2 and CDR3 sequences. For simplicity, the FWR and CDR peptides for each patient are serially numbered (e.g., CDR2-1 through CDR2-12 represent CDR2 peptides of $\left.\operatorname{LE} \operatorname{Ig} V_{H}\right)$.

These synthetic peptides were tested for their ability to stimulate Id-specific T cells using autologous PBMCs as APCs. Both LE-1 and LE- $2 \mathrm{~T}$ cells proliferated in response to full-length autologous CDR2 (CDR2-1) and CDR3 peptides, but not to an irrelevant CDR3 peptide from another patient (TL-CDR3-1) (Figure 3A). Similarly, when EBV-583 cells were used as APCs, enhanced proliferation response to autologous CDR2-1 and CDR3 peptides was observed in both LE $\mathrm{T}$ cell lines, and no response to the irrelevant CDR3 peptide was observed (Figure 3B). Cytokine responses (GM-CSF, IFN- $\gamma$, and TNF- $\alpha$ ) to the CDR2-1 and CDR3 peptides paralleled the proliferation responses (data not shown). The background responses to EBV-583 cells in the absence of peptide were minimal, indicating that the responses to alloantigens expressed by EBV-583 cells were insignificant. We next tested four additional CDR2 peptides (CDR2-7, -8, -9, and -12 ), each with one or more residues truncated from the fulllength CDR2-1 (see below); three FWR3 peptides; and one JH peptide (some of them overlap into adjacent CDR2 or CDR3 segments). It is important to note that these FWR and JH peptides were predicted to bind HLA-DRB $1 * 0701$ and/or -DRB $1 * 1501$ expressed by patient LE, and their ability to bind other class II alleles is not known. However, while all of the four CDR2 peptides induced dose-dependent proliferation by LE-1 T cells, the FWR3 and $\mathrm{JH}$ peptides did not, despite the wide range of peptide concentrations tested (Figure 3C). Similar results were obtained when autologous or HLA-matched heterologous PBMCs from patient VS were used as APCs (data not shown).

Likewise, four of six CDR3 peptides and one JH peptide from patient TL stimulated strong GM-CSF responses in TL-2 T cells, and lower, but significant, responses in TL-1 T cells (Figure 4A). These peptides also stimulated proliferation of TL T cells (data not shown). By contrast, a CDR1, an FWR2, a CDR2, and two FWR3 peptides failed to stimulate TL T cells. In patient BS, three of five CDR2 peptides and three of six CDR3 peptides induced strong GM-CSF responses in BS-1 and/or BS-2 T cell lines, while none of the four FWR3 peptides stimulated BS T cells (Figure $4 \mathrm{~B})$. Furthermore, the $\mathrm{CD} 8^{+} \mathrm{T}$ cell line from the patient BL (BL-3), although it failed to recognize autologous Id protein (Figure 2E), strongly responded to three of five CDR2, both of two CDR3, and one of five FWR3 peptides tested (Figure 4C). The CD4 $4^{+} \mathrm{T}$ cell line (BL-2), on the other hand, did not respond to most of the CDR2 and FWR3 peptides tested, except for a moderate response 

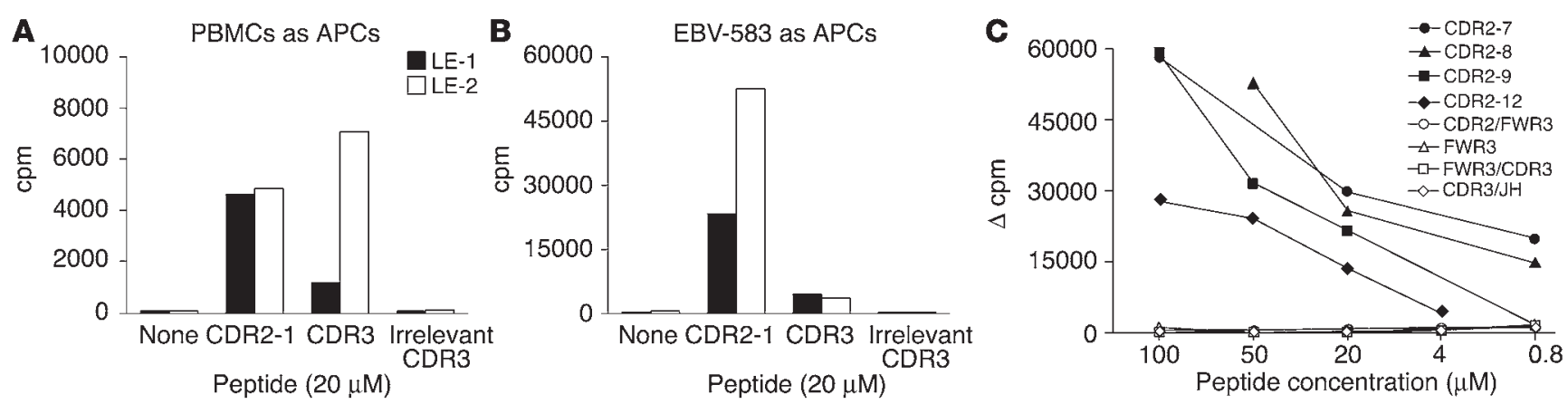

Figure 3

LE T cells responded to CDR, but not to FWR, peptides. (A and B) T cells were cultured with irradiated autologous PBMCs (A) or irradiated EBV-583 cells (B) in the absence or presence of $20 \mu \mathrm{M}$ LE-CDR2-1 or LE-CDR3. An equal amount of TL-CDR3 peptide was used as a specificity control. (C) LE-1 T cells were cultured with irradiated EBV-583 cells in the absence or presence of different doses $(0.8-100 \mu M)$ of LE-CDR2 and -FWR peptides, as indicated. The proliferation response (cpm or $\Delta \mathrm{cpm})$ from a representative experiment is shown.

to the CDR3 and FWR3-5 peptides. Notably, the majority (four of five) of FWR peptides did not stimulate BL T cells. T cell lines from these three patients (TL, BS, and BL) also elaborated IFN- $\gamma$ in response to the respective CDR peptides, but not to any FWR peptides (data not shown).

We next investigated whether the responses, described above, of established $\mathrm{T}$ cell lines to CDR peptides could also be observed in ex vivo, directly isolated, bulk PBMC samples. Accordingly, pre- and postvaccine PBMC samples from patients LE, TL, BS, and $\mathrm{BL}$ were cultured in the absence or presence of the same autologous CDR2 and CDR3 peptides in parallel (see Table 4, legend). As specificity controls, irrelevant CDR peptides from different patients were used. In all four patients, no significant cytokine responses were seen in prevaccine PBMCs, whereas postvaccine PBMCs showed modest, but specific, cytokine responses to CDR peptides (Table 4). These results are consistent with the hypothesis that Id vaccination induced tumor antigen-specific responses in these patients, and that the Id-specific $T$ cell lines established in vitro represent amplifications of such vaccineinduced $\mathrm{T}$ cells present in vivo.

Taken together, this analysis of the tumor-derived $\operatorname{Ig} \mathrm{V}_{\mathrm{H}}$ region peptides in four actively vaccinated FL patients suggests that there may be multiple, unique $\mathrm{T}$ cell epitopes in each Id protein and that the epitopes recognized are predominantly localized in the CDR domains.

Further characterization of LE T cell CDR2 epitope. The availability of sufficient numbers of PBMCs from patient LE, as well as an EBV-transformed cell line with four of six HLA class II alleles matched, EBV-583 (Table 1), allowed us to further characterize LE-CDR2 epitope as described below. Irradiated EBV-583 cells were pulsed with different concentrations of peptide (0.0013$200 \mu \mathrm{M}$ ) for 2-3 hours and washed before being added to $\mathrm{T}$ cells. Dose-response curves showed that significant prolifera-

\section{Figure 4}

Cytokine response by $\mathrm{T}$ cells to peptides derived from CDRs of $\mathrm{Ig}$ $\mathrm{V}_{\mathrm{H}}$. T cells from three additional patients, TL $(\mathbf{A}), \mathrm{BS}(\mathrm{B})$, and $\mathrm{BL}$ (C), were cultured with irradiated autologous PBMCs in the absence or presence of $50 \mu \mathrm{M}$ autologous CDR or FWR peptides (Table 3). GM-CSF responses from a representative experiment are shown. Similar results were obtained at lower antigen doses with BS and BL T cell lines (data not shown). tion of LE- 1 and LE-2 T cells was induced by as little as 0.16 and $0.8 \mu \mathrm{M}$ of CDR2-1 peptide, respectively (Figure $5 \mathrm{~A}$ ). While the proliferation response in LE- $1 \mathrm{~T}$ cells reached a plateau at about $10 \mu \mathrm{M}, \mathrm{LE}-2 \mathrm{~T}$ cells continued to show a dose-dependent increase in proliferation. The proliferation responses by both $\mathrm{T}$ cell lines were paralleled by an antigen-dose-dependent increase in the production of IFN- $\gamma$, TNF- $\alpha$, and GM-CSF, but not IL-4
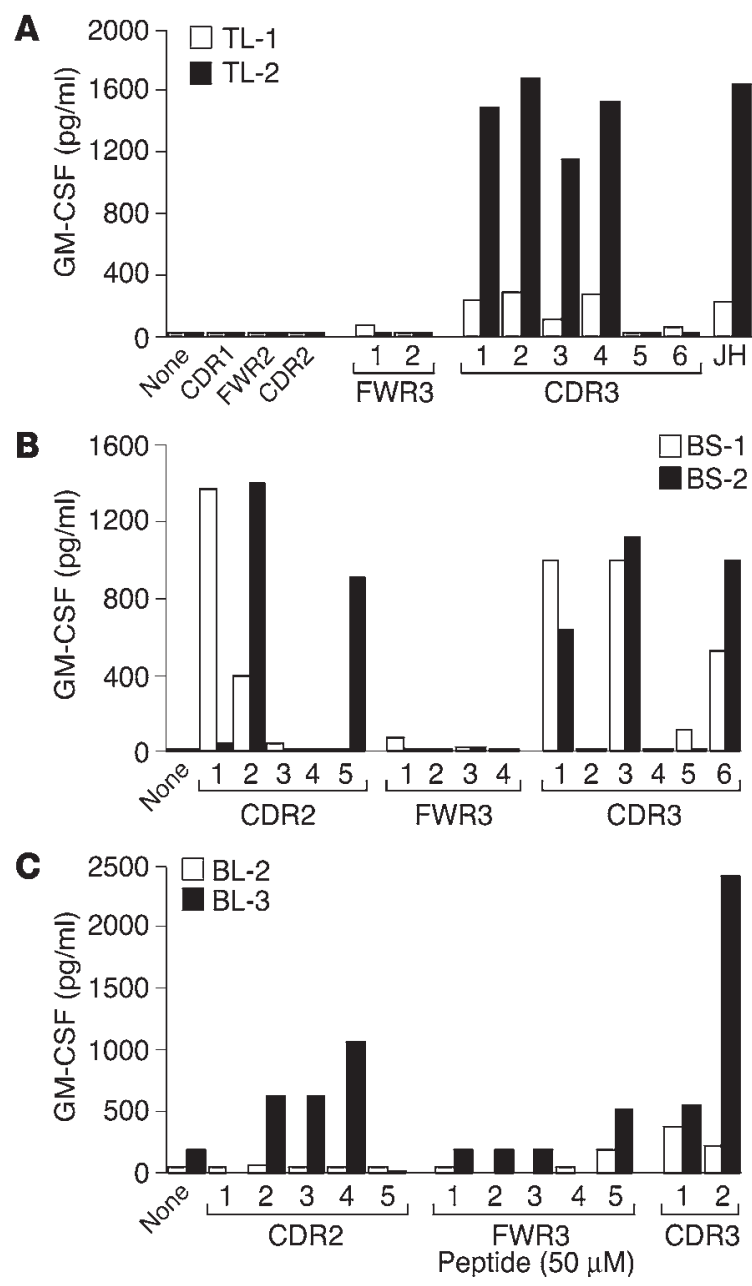
Table 4

Ex vivo PBMC responses to $\lg \mathrm{V}_{\mathrm{H}}$ peptides

\begin{tabular}{lccccc} 
Patient & \multicolumn{2}{c}{ Prevaccine PBMCs $^{\mathrm{A}}$} & \multicolumn{3}{c}{ Postvaccine PBMCs $^{\mathrm{A}}$} \\
& CDR2 & CDR3 & CDR2 & CDR3 & Irr. CDR \\
LE & $<15.6^{\mathrm{B}}$ & $<15.6$ & 172 & 304 & $<15.6$ \\
TL & $<15.6$ & $<15.6$ & 71 & 32 & $<15.6$ \\
BS & $<7.8$ & $<7.8$ & 39.3 & 126.5 & $<7.8$ \\
BL & $<7.8$ & $<7.8$ & 262 & 63 & $<7.8$ \\
\hline
\end{tabular}

APrevaccine and postvaccine PBMCs were cultured in parallel with 50 $\mu \mathrm{M}$ of the same autologous Id-derived CDR2 and CDR3 peptides. The autologous peptides used were as follows: for LE, CDR2-1 and CDR3; for TL, CDR2 and CDR3-1; for BS, CDR2-1 and CDR3-6; and for BL, CDR2-4 and CDR3-2. As controls, CDR peptides from other irrelevant patients (Irr. CDR) were used. BValues indicate GM-CSF (pg/ml) secreted in 6 days of culture with the indicated peptides. The background response in the absence of peptides was $<15.6$ or $<7.8$, depending on the initial dilution of the culture supernatant.

or IL-10 (Figure 5B and data not shown). Similar results were obtained when the antigen was left for the entire period of culture (data not shown).

The full-length CDR2 peptide (CDR2-1) recognized by the LE T cells is 17 amino acids long. It is possible that this peptide undergoes further processing in APCs, and the minimal epitope recognized by $T$ cells could be a smaller peptide. To address this issue, a synthetic CDR2 peptide library was made by progressive truncations from the amino or carboxyl terminus, and the resulting peptides were used to stimulate LE-1 and LE-2 T cells (Figure 5C). Sequential truncations of CDR2-1 peptide revealed that the first two amino acids at the amino terminus and the last four amino acids at the carboxyl terminus were dispensable, since synthetic peptides lacking these residues were able to induce significant proliferation of LE- 1 and LE- $2 \mathrm{~T}$ cells. These truncated peptides (CDR2-2, -3, -7, -8, and -9) induced a dose-dependent proliferation response (Figure 3C; and Figure 5C, legend). These results suggested that a shorter peptide (corresponding to position 52-61 of Ig $V_{H}$ ) might constitute the core of the CDR2 epitope. This was confirmed by the observation that an 11-mer peptide (CDR2-12, ${ }_{52}$ TNTSSYISYAD $_{61}$ ) comprising the core of LE-CDR2 stimulated

\section{Figure 5}

Dose-response curves of LE T cells and determination of a minimal CDR2 T cell epitope. (A) The EBV-583 cells were incubated at $37^{\circ} \mathrm{C}$ for 2-3 hours with the indicated amounts of LE-CDR2-1 peptide. After three washes, peptide-pulsed EBV-583 cells were irradiated and cultured with $T$ cells. The proliferation responses by LE-1 (filled circles) and LE-2 (open circles) T cells are shown. (B) Culture supernatants from parallel experiments, as described for $\mathbf{A}$, were collected, and cytokine responses were determined. (C) LE T cells were cultured with irradiated EBV-583 cells in the absence or presence of $50 \mu \mathrm{M}$ individual peptide from an LE-CDR2 library. Proliferation responses $(\Delta \mathrm{cpm})$ from a representative experiment are shown. The responses to 10 and $1 \mu \mathrm{M}$ of peptide ITNTSSYISYADSVK (CDR2-2) were 37,026 and $19,981 \Delta \mathrm{cpm}$, respectively. The responses to 10 and $1 \mu \mathrm{M}$ of peptide TNTSSYISYADSVK (CDR2-3) were 320,602 and 14,069 $\Delta \mathrm{cpm}$, respectively. Dose-response curves for other maximally stimulatory peptides, YITNTSSYISYADSV (CDR2-7), YITNTSSYISYADS (CDR2-8), and YITNTSSYISYAD (CDR2-9), are depicted in Figure $3 C$. A similar pattern of response was seen with $5 \times 10^{4}$ and $2 \times 10^{5} \mathrm{~T}$ cells (data not shown). a dose-dependent proliferation and cytokine responses in LE T cells (Figure 3C and data not shown). In this minimal epitope, the amino-terminal residues, threonine $(\mathrm{T})$ and asparagine $(\mathrm{N})$, and the carboxyl-terminal aspartic acid (D) seem to be critical for a functional epitope, since deletion of these residues caused significant loss or abrogation of $\mathrm{T}$ cell proliferation (peptides CDR2-5, -6, -10, and -11; Figure 5C). Analysis of LE Ig $\mathrm{V}_{\mathrm{H}}$ amino acid sequence by algorithm-based epitope prediction revealed many 15 -mer peptides that could potentially bind DRB $1 * 0701$ and DRB1*1501 (both alleles expressed by patient LE) with binding scores between 18 and 26, and several of them contained the motif TNTSSYISYAD in different registers. Potential binding of this motif to other class II alleles of patient LE could not be evaluated, as they were not available in the database used (see ref. 31). However, it should be noted that the delineation, described above, of a minimal epitope was based on studies using LE T cell lines that possibly consist of multiple clones of $\mathrm{T}$ cells, and therefore the presence of additional epitopes may be anticipated.

Next, we determined the frequency of peptide-specific $T$ cells in LE T cell lines by intracellular cytokine staining of the T cells following overnight antigen stimulation using EBV-583 cells as APCs. Stimulation with $20 \mu \mathrm{M}$ CDR2-1 peptide induced robust IFN- $\gamma$ and TNF- $\alpha$ production in more than $95 \%$ of LE- $1 \mathrm{~T}$ cells (Figure 6). Dose-response studies showed that as little as $0.8 \mu \mathrm{M}$ of CDR2-1 peptide stimulated IFN- $\gamma$ and TNF- $\alpha$ responses in
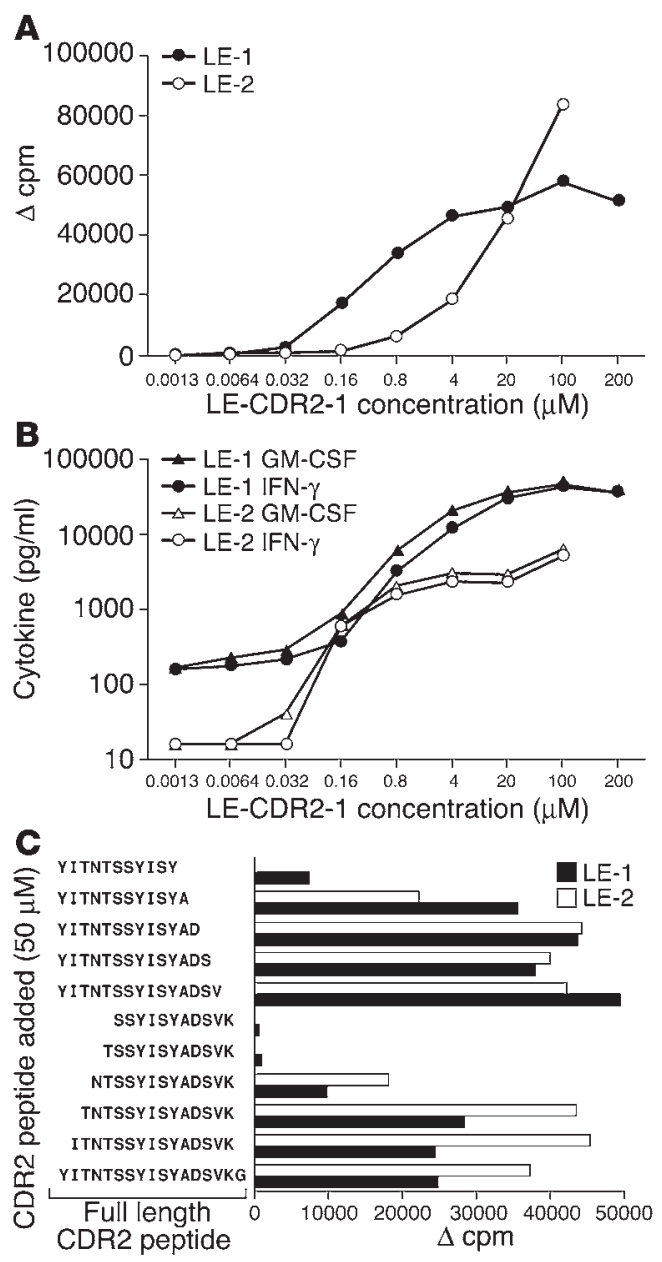

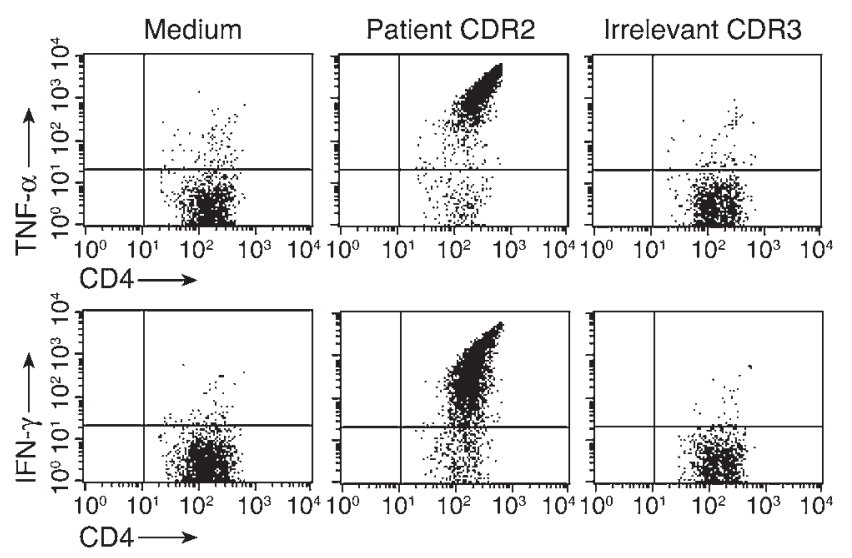

Figure 6

LE-1 T cells produced Th1 cytokines in response to CDR2-1 peptide. T cells were cultured with irradiated EBV- 583 cells in the absence or presence of $20 \mu \mathrm{M}$ LE-CDR2-1 or TL-CDR3 peptide overnight at $37^{\circ} \mathrm{C}$. Intracellular cytokine responses, TNF- $\alpha$ (top panels) and IFN- $\gamma$ (bottom panels), from a representative experiment are shown. Similar results were obtained when CD3-depleted autologous PBMCs were used as APCs (data not shown).

about $83 \%$ of LE-1 T cells (data not shown). Stimulation with an irrelevant peptide (0.8-100 $\mu \mathrm{M}$, TL-CDR3-1) did not induce any significant cytokine production compared with the medium controls (Figure 6 and data not shown). Similar results were obtained when CD3-depleted autologous or HLA-matched heterologous PBMCs were used as APCs (data not shown). Additional experiments showed that several truncated CDR2 peptides (CDR2-7, -8, -9 , and -12 ) also were able to induce strong intracellular cytokine responses in LE T cells (data not shown). As observed before with Id protein, these peptides did not induce IL-4 or IL-10 production in LE-1 T cells (data not shown).

Thus, it was observed that LE T cells exhibited significant responses to the CDR2 peptide at doses as low as $200 \mathrm{nM}$, and an 11-amino acid peptide constituted the core of this epitope. Several peptide motifs containing this core epitope were predicted to bind class II alleles of patient LE. Stimulation of LE T cells with this epitope resulted in Th1-type cytokine responses.

Are the CDR2 T cell epitopes of Ig $V_{H}$ derived by somatic mutation? It is well documented that somatic mutations in variable heavy chain and variable light chain genes of Ig result in clonotypic expression of unique surface Ig receptor in normal and malignant B cells (7-12). Therefore, it is possible that the T cell epitope(s) identified above may have been generated by somatic mutation of $\operatorname{Ig} \mathrm{V}_{\mathrm{H}}$ genes. To address this possibility, tumor $\operatorname{Ig} \mathrm{V}_{\mathrm{H}}$ nucleotide sequences from patients were compared with consensus sequences of various germ-line $\mathrm{Ig} \mathrm{V}_{\mathrm{H}}$ gene families, available in the database (V BASE Index, MRC Centre, Cambridge, United Kingdom), to identify the $\operatorname{Ig} \mathrm{V}_{\mathrm{H}}$ gene they were most likely derived from. Comparison with the germ-line $\operatorname{Ig} \mathrm{V}_{\mathrm{H}}$ genes revealed several point mutations that result in amino acid substitutions throughout the CDR2 and CDR3 regions of tumor $\mathrm{Ig} \mathrm{V}_{\mathrm{H}}$ (Figure $7 \mathrm{~A}$ and data not shown). In particular, LE tumor Ig $V_{H}$ CDR2 sequence had four unique amino acid substitutions at the amino-terminal end (Figure 7A). Synthetic peptides from the three candidate, closely related germline CDR2 sequences were tested for their ability to stimulate LE $\mathrm{T}$ cells. As observed before, the stimulatory peptides (LE-CDR2-1 and LE-CDR2-9) induced strong cytokine responses in LE-1 T cells. By contrast, cytokine responses to the three germ-line CDR2 peptides were insignificant, as seen with the nonstimulatory control peptides LE-CDR3/JH and TL-CDR-2 (Figure 7, B and C).

It is possible that the absence of response to germ-line CDR2 peptides is due either to their inability to bind the HLA class II alleles of patient LE or to the absence of appropriate $\mathrm{T}$ cells in the LE-1 T cell line to recognize the germ-line CDR2 peptides. However, analysis of the predicted binding of the germ-line CDR2 peptides to HLA-DRB1*0701 and -DRB1*1501 (both alleles expressed by patient LE) revealed that they had similar binding scores to that of the stimulatory peptide LE-CDR2-1 (Table 5). Furthermore, studies with EBV transformants expressing either HLA-DRB $1 * 0701$ or -DRB1*1501 suggest that these alleles may be involved in presenting a cognate peptide (e.g., LE-CDR2-1) to LE T cells (see below). The control peptide TL-CDR2 showed higher binding scores but nevertheless was nonstimulatory. The ability of the germ-line peptides to bind other class II alleles of patient LE, which were not available in the database, is unknown. Based on these findings, it seems likely that the absence of response to germline peptides is due not to their failure to bind HLA molecules of the host, but rather to the absence of potentially responding $\mathrm{T}$ cells in the LE-1 $\mathrm{T}$ cell line.

These results are consistent with the possibility that LE-1 T cells recognized a unique CDR2 epitope that may be a product of somatic mutation. Alternatively, the results could be due to differences in the patient's actual and consensus germ-line gene sequences or to a previously unidentified germ-line gene in this patient.

$M H C$ association of Id- and tumor-specific $T$ cell responses. The autologous Id- and tumor-reactive T cells described above express TCR $\alpha \beta$. Numerous reports have established that both $\mathrm{CD}^{+}$and $\mathrm{CD}^{+} \mathrm{T}$ cells with TCR $\alpha \beta$ recognize nominal antigenic peptides in the context of self MHC class II and class I molecules, respectively (35). Two independent approaches were taken to demonstrate MHC association of Id- and tumor-specific T cell responses. First, PBMCs and EBV cell lines from heterologous patients that shared one or more HLA class I and/or class II alleles with patient LE were used as APCs to stimulate LE- 1 and LE- 2 T cells. Both these $\mathrm{T}$ cell lines consisted of at least $98 \% \mathrm{CD}^{+} \mathrm{T}$ cells and were stimulated by autologous Id presented by allogenic PBMCs that shared several HLA class II alleles (patient VS), but not by PBMCs from patients HR, BE, RB, SG, and NC (Figure 8A and Table 1). In particular, the alleles DRB $1 * 1501$, DQB $1 * 0602$, and DRB5 ${ }^{*} 0101$ are shared by LE and VS, and PBMCs from patients that did not express these alleles, as mentioned above, failed to stimulate LE $\mathrm{T}$ cells. Furthermore, EBV transformants from two different patients - EBV-583 and EBV-1087 - that expressed three or four class II alleles that matched with LE (including those mentioned above) were able to present LE-CDR2-1 peptide to LE T cells (Figure $8 \mathrm{~B}$ and Table 1$)$. The EBV transformants from a third patient, EBV-1088, expressing DQB $1 * 02$ and DRB $4 * 01$ that matched with LE, induced a low level of response in LE-1 T cells, whereas EBV-1363 from a fourth patient with no matching class II allele failed to stimulate LE T cells (Figure 8B and Table 1). Interestingly, with the exception of a weak allogenic response against antigen-unpulsed PBMCs from patient RB, there was no significant allogenic response by LE T cells to any of these heterologous APCs. Together, these results suggest that it is possible that one or more of the HLA class II molecules DRB1*1501, DQB1*0602, and DRB $5 * 101$ could be involved in antigen presentation to LE 


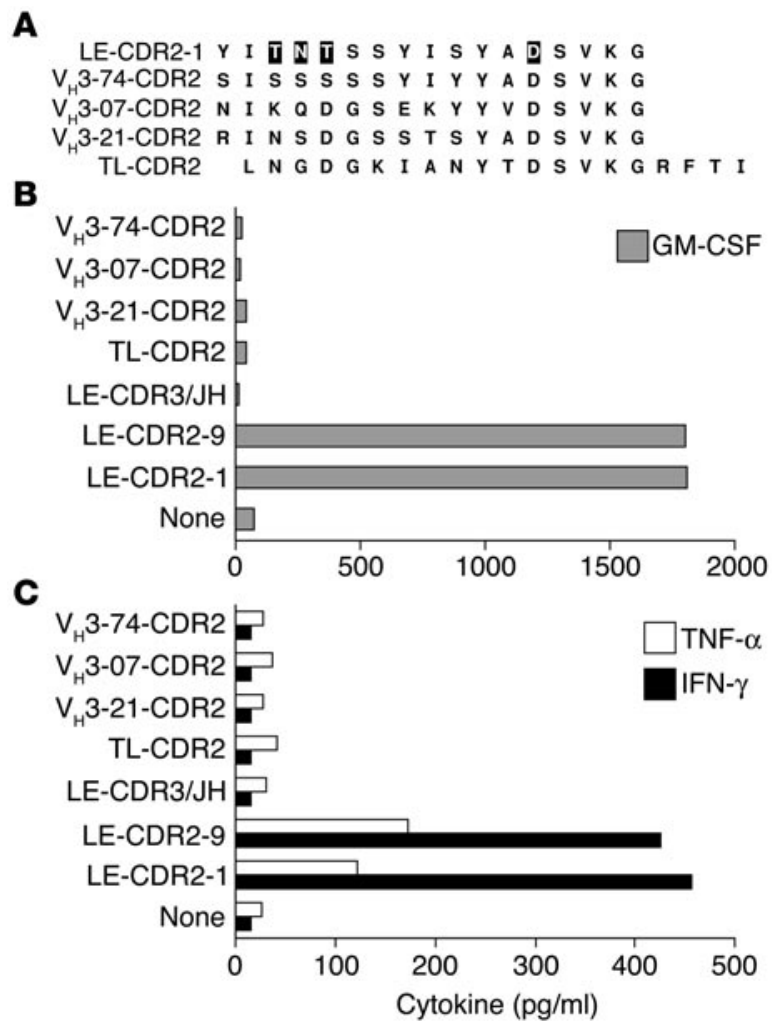

T cells. Similarly, TL-1 T cells were stimulated by autologous Id protein and TL-CDR3-1 peptide when autologous PBMCs or partially HLA-matched PBMCs from patient JR (sharing DRB $1 * 07$, DRB $3 * 02$, and DRB $4 * 01$ with patient TL) were used as APCs, but not when mismatched PBMCs from patient LK were used (Figure 8 , C and D, and Table 1). However, JR PBMCs induced only about $30-40 \%$ of the response induced by autologous TL PBMCs, suggesting that additional HLA class II molecules not expressed by JR may also be involved in antigen presentation to TL T cells.

In the second approach, anti-HLA Ab's were used to inhibit $\mathrm{T}$ cell responses to autologous Id protein, peptides, or autologous tumor. Addition of anti-DR, anti-DP, or anti-DQ Ab's moderately inhibited (30-78\%) LE-1 and LE-2 T cell response to the CDR2-1 peptide (Figure 8E). However, addition of pan-class II Ab's significantly inhibited (>85\%) the response by both the $\mathrm{T}$ cell lines, and less than $10 \%$ inhibition was seen with isotype-matched control Ig (Figure 8E). Although these results did not identify the class II molecule(s) involved, they are consistent with the above-mentioned results with heterologous APCs and suggest that all of the three class II molecules (HLA-DP, -DQ, and -DR) may be involved in activating different populations of $\mathrm{T}$ cells present in both LE T cell lines. Similarly, while pan-class II Ab's inhibited (90\%) TL-1 and TL-2 proliferation response to autologous Id protein, isotype control Ig or anti-class I Ab's did not (Figure 8F). Likewise, the proliferation of BL-1 (CD4 line) T cells in response to autologous tumor was inhibited by anti-class II, but not by anti-class I, Ab's (Figure 8G), and conversely the proliferation of BL-3 (CD8 line) T cells in response to autologous tumor was inhibited by anti-class I, but not by anti-class II, Ab's (Figure 8G). Additional experiments were performed to further delineate the HLA molecules involved in the stimulation of BL T cells. The antitumor response by the

\section{Figure 7}

LE-1 T cells did not respond to germ-line CDR2 peptides. (A) Amino acid sequences of LE-CDR2-1, germ-line CDR2 peptides from three members of the $\mathrm{V}_{\mathrm{H}} 3$ family, and a control TL-CDR2 peptide are compared. The unique and critical residues in LE-CDR2-1 are highlighted. (B and $\mathbf{C}$ ) T cells were cultured with irradiated autologous PBMCs in the absence (None) or presence of $100 \mu \mathrm{M}$ of indicated peptide. LECDR2-1 and LE-CDR2-9 peptides were used as positive controls, and LE-CDR3/JH and TL-CDR2 peptides as negative controls. Cytokine responses from a representative experiment are shown.

CD4 line (BL-1) was moderately (about 50\%) inhibited by anti-DR as well as anti-DQ mAb's, suggesting that both DR and DQ molecules may be involved in the activation of BL-1 T cells. On the other hand, two different anti-DR52 mAb's failed to inhibit the responses, suggesting that the DRB3*01 and DRB $3 * 02$ molecules expressed by the patient may not be involved in the activation of BL-1 T cells (Figure 8H). The antitumor response by the CD8 $\mathrm{T}$ cell line (BL-3) was almost completely inhibited by anti-HLA-B*08 $\mathrm{mAb}$, but not by any of the class II-specific Ab's tested (Figure $8 \mathrm{H}$ ), and it is likely that this response is HLA-B* 08 restricted.

In all the $\mathrm{T}$ cell lines investigated, except BL-3, multiple HLA molecules seem to be involved in the activation of $\mathrm{T}$ cells, and this is consistent with the possible heterozygous nature of these $\mathrm{T}$ cell lines. Overall, these results suggest that both the CD4 and the CD8 $\mathrm{T}$ cell responses to Id proteins, Id peptides, and/or autologous tumor were associated with HLA class II and class I molecules, respectively.

\section{Discussion}

Identification of clinically relevant tumor-rejection antigens recognized by human $\mathrm{T}$ cells has facilitated the development of novel strategies for active immunotherapy of human cancers. For example, a number of $\mathrm{T}$ cell epitopes have been well characterized for human melanoma (1-3), renal cell carcinoma (36), and breast carcinoma (37) antigens. Functional CD4 and CD8 T cell responses

Table 5

Predicted binding of germ-line and somatically mutated Ig $V_{H}$ peptides

\begin{tabular}{|c|c|c|}
\hline \multirow[t]{2}{*}{ Peptide source ${ }^{A}$} & \multirow[t]{2}{*}{ Sequence ${ }^{B}$} & Binding score ${ }^{c}$ \\
\hline & & DRB1*0701 \\
\hline LE-CDR2-1 & YITNTSSYISYADSV & 10 \\
\hline VH3-74-CDR2 & SISSSSSYIYYADSV & 10 \\
\hline VH3-07-CDR2 & NIKQDGSEKYYVDSV & 14 \\
\hline$V_{H} 3-21-C D R 2$ & RINSDGSSTSYADSV & 18 \\
\hline \multirow[t]{2}{*}{ TL-CDR2 } & GDGKIANYTDSVKGR & 16 \\
\hline & & DRB1*1501 \\
\hline LE-CDR2-1 & ITNTSSYISYADSVK & 14 \\
\hline $\mathrm{V}_{\mathrm{H}} 3-74-\mathrm{CDR} 2$ & ISSSSSYIYYADSVK & 10 \\
\hline$V_{H} 3-07-C D R 2$ & KQDGSEKYYVDSVKG & 10 \\
\hline$V_{H} 3-21-C D R 2$ & RINSDGSSTSYADSV & 8 \\
\hline TL-CDR2 & DGKIANYTDSVKGRF & 24 \\
\hline
\end{tabular}

AThe germ-line peptides are identified with the prefix $\mathrm{V}_{\mathrm{H}} 3$, and LE-CDR2-1 and TL-CDR2 represent the tumor Id-derived peptides from patients LE and TL. BPeptide sequences giving the highest binding score with HLADRB $1{ }^{*} 0701$ and HLA-DRB1*1501 alone are depicted. ${ }^{\circ}$ Analysis was done using the SYFPEITHI database (see ref. 31). 
A

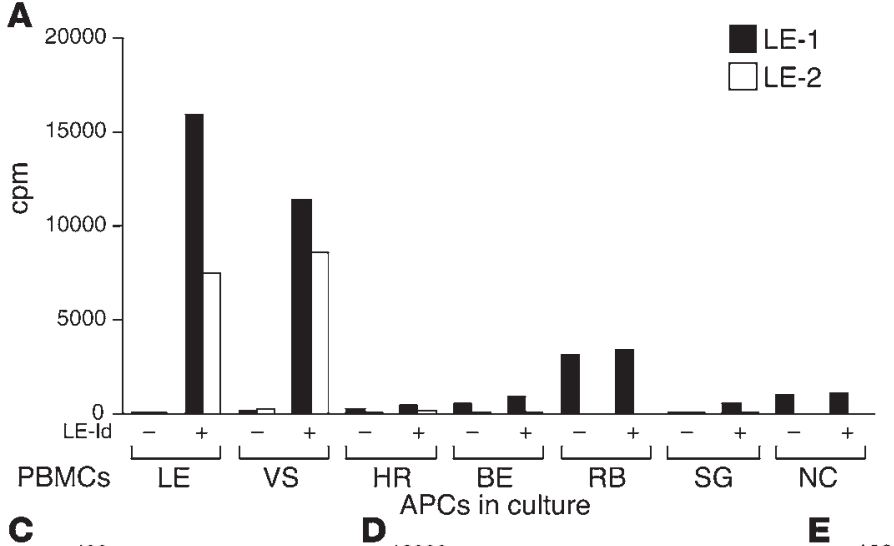

B $_{60000}$
$\square \mathrm{LE}-1$
$\quad \square \mathrm{LE}-2$

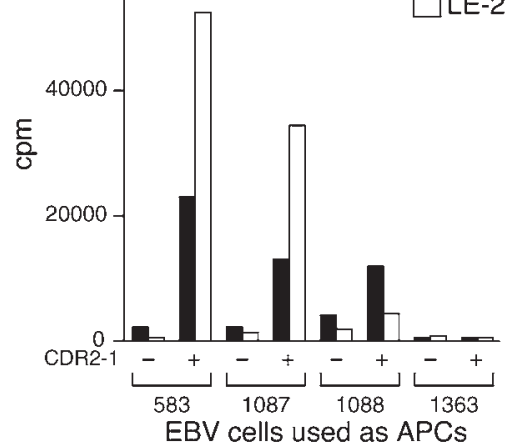

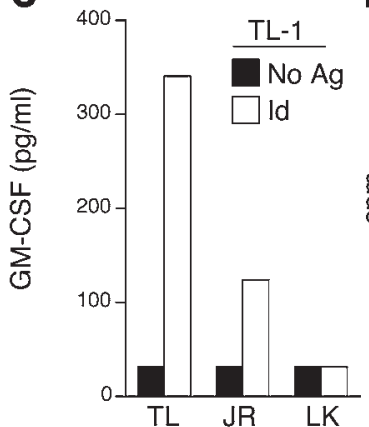

PBMCs used as APCs

F

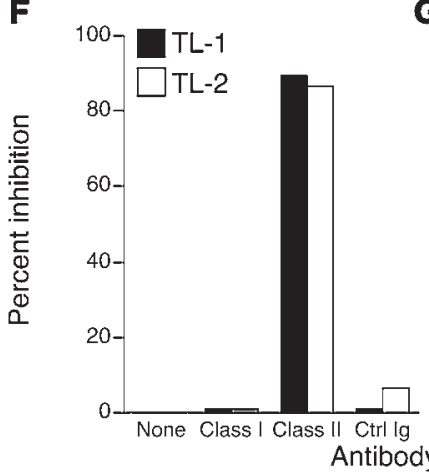

$D_{12000-}$

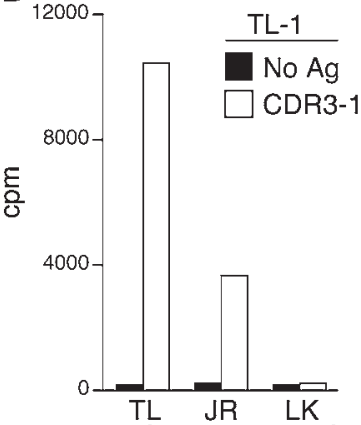

$G$

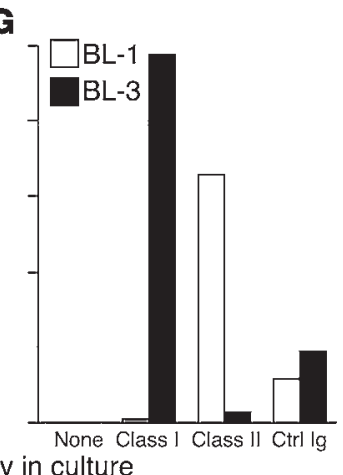

${ }_{100-\square L E-1}$

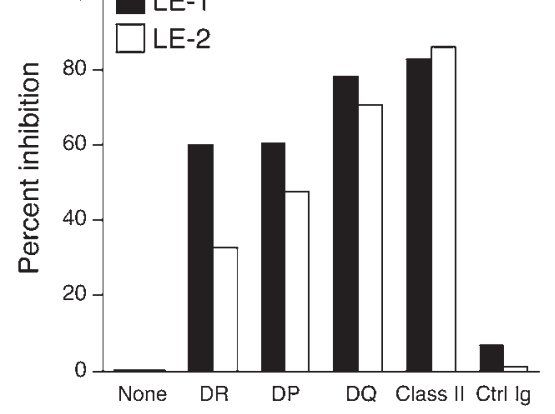

H

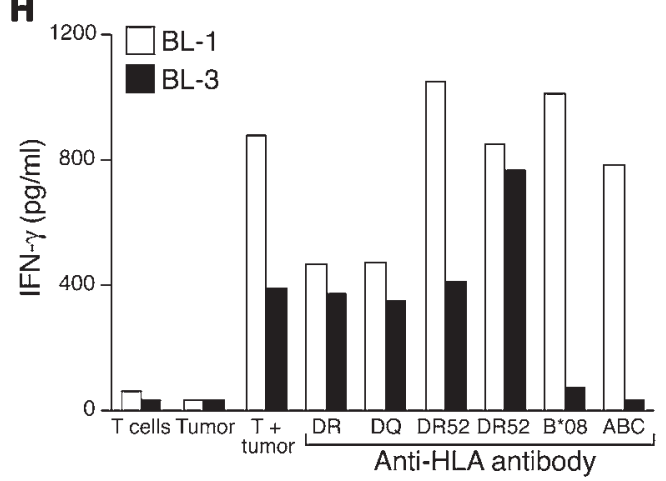

Figure 8

T cell response to Id, peptides, or autologous tumor was HLA associated. (A) LE T cells were cultured with irradiated autologous PBMCs (LE) or HLA-matched (VS) or HLA-mismatched (HR, BE, RB, SG, and NC) heterologous PBMCs in the absence (-) or presence $(+)$ of $100 \mathrm{\mu g} / \mathrm{ml}$ LE-Id. The proliferation response $(\mathrm{cpm})$ was measured by $\left[{ }^{3} \mathrm{H}\right]$ thymidine incorporation. $(\mathbf{B})$ The proliferation response of LE T cells to LE-CDR2-1 peptide was measured using irradiated EBV cells as APCs. (C and D) The proliferation and cytokine responses of TL T cells to TL-Id and TL-CDR3-1 peptide, respectively, were measured using autologous PBMCs or matched (JR) or unmatched (LK) heterologous PBMCs as APCs. (E and F) In the inhibition experiments, the indicated T cells were cultured with irradiated autologous PBMCs and $10 \mu M$ LE-CDR2-1 peptide (E) or TL-CDR3-1 (F) in the absence or presence of anti-HLA mAb's or control (ctrl) Ig. (G and H) BL T cells were cultured with irradiated autologous tumor cells in the absence or presence of the indicated mAb's. The proliferation responses in the absence of Ab's (None) were 106,658 (LE-1), 86,511 (LE-2), 5,930 (TL-1), 23,461 (TL-2), 107,223 (BL-1), and 13,244 (BL-3). Results from a representative experiment are shown. Ag, antigen.

against the $\mathrm{B}$ cell tumor antigen Id have also been described in patients with different types of B cell malignancies $(17,38,39)$, especially after active immunization with Id protein. However, information on the precise nature of antigenic epitopes in Id protein recognized by the responding T cells is limited. Previous studies have suggested that $T$ cells from patients with B cell malignancies could be stimulated in vitro to recognize synthetic peptides corresponding to the Ig $\mathrm{V}_{\mathrm{H}}$ CDR segments (19-24). Nonetheless, the precise epitopes recognized by $\mathrm{T}$ cells in vivo are entirely unknown. In this study we have shown that the majority of Id-vac- cinated patients exhibited Id-specific $\mathrm{T}$ cell responses, and only a fraction ( 3 of 13 ) of the vaccinated patients failed to do so. However, it is unlikely that this failure is due to a lack of T cell epitopes in their Id, because epitope-prediction analysis revealed several motifs that could potentially bind one or more HLA molecules expressed by these patients. Whether the lack of $\mathrm{T}$ cell response in these patients is due to clonal deletion or peripheral tolerance remains to be determined. Furthermore, we have analyzed $\mathrm{T}$ cell lines generated from FL patients who had been actively immunized with the unique Id protein expressed by their tumors to 
identify functional T cell epitopes. The characteristics of Id-specific responses observed with the in vitro-established antigen-specific $T$ cell lines might be clinically relevant, as they paralleled ex vivo responses seen in the postvaccine PBMC samples.

The main goal of this study was to elucidate the precise nature of the antigenic epitopes recognized by human Id-specific $\mathrm{T}$ cells. The intrinsic variability in nucleotide sequence generated by VDJ recombination, nontemplated addition of nucleotides in the CDR segments of $I g \mathrm{~V}_{\mathrm{H}}$, and somatic point mutations can all produce potentially unique antigenic epitopes (7-12). In all eight independently derived $\mathrm{T}$ cell lines from the four patients studied, the functional $\mathrm{T}$ cell epitopes localized to the hypervariable regions (CDR2 and CDR3) of corresponding tumor $\operatorname{Ig} \mathrm{V}_{\mathrm{H}}$. These $T$ cell responses were uniquely patient-specific, as they responded only to peptides derived from autologous CDR sequences. Besides, the CDR peptides stimulated cytokine responses in postvaccine PBMCs from these four patients in a patient-specific manner, suggesting that the responses described above for $\mathrm{T}$ cell lines may represent that of such vaccine-induced $\mathrm{T}$ cells present in vivo. There was no evidence of endogenous responses to these CDR epitopes in the tumor-bearing host prior to vaccination that were then amplified following Id vaccination. It also became clear that there is more than one immunodominant epitope in each Id protein, raising the possibility of a polyclonal $\mathrm{T}$ cell response against this antigen. Such a polyclonal response would be valuable to maintain a sufficient pool of specific T cells against tumor antigen(s) and might help to reduce the chance of immune escape variants and to establish long-lasting antitumor immunity following active vaccination (40-42).

The detailed study of a CDR2 epitope in $\mathrm{Ig} \mathrm{V}_{\mathrm{H}}$ of patient LE demonstrated the immunodominant nature of a number of overlapping CDR2 peptides. These peptides stimulated the majority of LE T cells to produce proinflammatory cytokines such as IFN- $\gamma$, TNF- $\alpha$, and GM-CSF, as evident from intracellular cytokine staining. Elaboration of Th1 cytokines by tumor-specific $\mathrm{CD}^{+} \mathrm{T}$ cells has been shown to have both direct and indirect effects on the induction and maintenance of antitumor immunity (43). The marked absence of inhibitory cytokines such as IL-10 following antigen (Id protein or peptide) stimulation might help prevent negative-feedback regulation of the generation and function of antigen-specific effector $\mathrm{T}$ cells (44-46).

Unlike CDR peptides, the majority of FWR peptides failed to stimulate autologous $\mathrm{T}$ cell lines from all of the four FL patients studied, except one JH peptide (patient TL) and one FWR3 peptide (patient BL). It is important to note that all FWR peptides used in this study had similar predicted binding affinity, as did the CDR peptides with one or more HLA molecules in the corresponding patient. These results, therefore, support the notion not only that FWR peptides were cryptic, but also that the frequency of $\mathrm{T}$ cells capable of responding to FWR peptides might have been very low and that these $\mathrm{T}$ cells may have been lost during the generation of Id-specific $\mathrm{T}$ cell lines. The precursor frequency of T lymphocytes able to recognize unmutated self-antigen (e.g., FWR peptides) is likely to be low in peripheral blood (47), and this did not significantly change following Id vaccination. Enhanced $T$ cell responses to CDR peptides were seen when APCs expressing high levels of HLA and costimulatory molecules (e.g., EBV-583 cells) were used; however, under the same conditions, the response to FWR peptides remained at the background levels. In contrast, by deliberate in vitro restimula- tions with FWR peptides using CD40-activated B cells as APCs, cytotoxic $\mathrm{T}$ cell lines could be generated against FWR peptides in some chronic lymphocytic leukemia and FL patients (25), and this was improved using heteroclitic FWR peptides with enhanced binding to HLA-A2 molecule (26). At this time our data do not provide evidence that in vivo $\mathrm{T}$ cell responses actually elicited in Id-vaccinated patients are directed against FWRs of $\operatorname{Ig} \mathrm{V}_{\mathrm{H}}$, and the reason for this discrepancy is not clear.

Furthermore, peptides from three related $\left(\mathrm{V}_{\mathrm{H}} 3\right.$ family) germline CDR2 sequences failed to stimulate LE T cells despite their significant sequence similarity with LE-CDR2. In addition, analysis of the predicted binding ability showed that the germ-line CDR2 peptides had binding scores similar to that of LE-CDR2 peptide. This suggested that T cells capable of recognizing germ-line peptides were probably absent; whether this was due to clonal deletion or peripheral tolerance is unclear. This is consistent with the importance of critical substitutions at the amino terminus of LE-CDR2 ( $\mathrm{Ig} \mathrm{V}_{\mathrm{H}}$ position $50-52 \mathrm{a}$ in ${ }_{50}$ YITN $_{52 \mathrm{a}}$ TSSYISYAD $_{61}$ ). Somatic mutation in FL B cells has been shown to selectively generate novel sites (threonine and asparagine) for $\mathrm{N}$-linked glycosylations in CDR segments, more frequently in CDR2 (48), and this may increase the possibility of generating unique antigenic epitopes. Interestingly, LE-CDR2 harbors such amino acid residues as a critical component of the natural antigenic epitope (YITNTSSYISYADSVKG), and synthetic peptides with deletions of these residues (e.g., SSYISYADSVKG) were unable to stimulate LE T cells. Furthermore, epitope-prediction analysis of $\mathrm{LE} \operatorname{Ig} \mathrm{V}_{\mathrm{H}}$ revealed several peptides that included the motif TNTISYSSYAD (the minimal epitope described above), which could potentially bind at least HLADRB $1 * 0701$ and -DRB1*1501, molecules expressed by patient LE. It is also possible that the patient would have responded if the patient had been vaccinated with an alternate idiotype that also contained an 11-mer sequence that could bind and be presented by the patient's HLA allele(s). However, additional studies are required to determine whether these amino acid substitutions are a result of the somatic mutation process commonly observed in germinal center B cells (7-12). Alternatively, it is possible that the unique CDR2 epitope in LE tumor Ig $V_{H}$ represents an as-yet unidentified, unmutated germ-line sequence.

Results of the studies with HLA-matched and unmatched APCs, and inhibition of $\mathrm{T}$ cell responses in the presence of antiHLA class II Ab's, have demonstrated that multiple HLA molecules may be involved in the activation of Id-specific $\mathrm{CD}^{+} \mathrm{T}$ cell lines. This is consistent with the fact that exogenous antigens are processed primarily through the MHC class II pathway (35). These $\mathrm{CD}^{+} \mathrm{T}$ cells could play an important role in the induction and maintenance of antitumor immunity (43). However, because of the possible multiclonal or oligoclonal nature of $\mathrm{T}$ cell lines and multiple HLA molecules expressed by the APCs used in the study, we were unable to identify specific HLA alleles involved. On the other hand, autologous tumor-raised $\mathrm{T}$ cell lines consisted of both $\mathrm{CD}^{+}(\mathrm{BL}-1)$ and $\mathrm{CD}^{+}(\mathrm{BL}-3) \mathrm{T}$ cells, and their responses were class II or class I associated, respectively. In the case of the CD8 ${ }^{+} \mathrm{BL}-3 \mathrm{~T}$ cells, the restriction element seems to be HLA-B*08. It is possible that the endogenous putative tumor antigen(s) was presented by class I as well as class II molecules. Simultaneous induction of both subsets of $\mathrm{T}$ cells capable of responding to tumor antigen(s) by a therapeutic cancer vaccine is probably desirable. 
In conclusion, we have shown that $\mathrm{T}$ cell lines derived from actively immunized FL patients recognized multiple, unique, and patient-specific antigenic determinants of Id in an MHC-associated fashion. The dominant antigenic epitopes localized to the hypervariable regions (CDRs) of tumor $\mathrm{Ig} \mathrm{V}_{\mathrm{H}}$. It should be noted that the contribution of Ig light chain, and antigenic epitopes it might harbor, has not been addressed in our study. The association of Id-specific T cells with the achievement of molecular remissions in vaccinated patients (17) suggests that the responses against these newly identified $\mathrm{T}$ cell epitopes may be clinically relevant. The presence of multiple $\mathrm{T}$ cell epitopes in individual Id proteins, the likelihood of these epitopes to functionally associate with more than one HLA molecule, and the activation of both $\mathrm{CD}^{+}$and $\mathrm{CD}^{+} \mathrm{T}$ cell subpopulations that can recognize the autologous tumor B cells ( $S$. Baskar, unpublished observation) support the hypothesis that vaccination with a defined tumor-specific antigen can elicit robust and polyclonal $\mathrm{T}$ cell responses. As additional $\mathrm{T}$ cell epitopes in human Id proteins are characterized, such defined antigenic epitopes may serve as candidates for novel peptide-vaccine strategies, for in vitro expansion of antigen-specific T cells for adoptive immunotherapy, and as reagents for immune monitoring of vaccinated patients.

\section{Acknowledgments}

We thank R. Pennington and S. Grove for excellent technical help, T. Watson for patients' blood samples, S. Topalian (Surgery Branch, NIH, Bethesda, Maryland, USA) for EBV cell lines, and J. Barb for secretarial assistance. All the HLA typing was done at the Warren G. Magnuson Clinical Center (Department of Transfusion Medicine, NIH HLA Typing Laboratory, Bethesda, Maryland, USA). This study has been funded in whole or in part with federal funds from the National Cancer Institute, NIH, under contract no. N01-CO12400. The content of this publication does not necessarily reflect the views or policies of the Department of Health and Human Services, nor does mention of trade names, commercial products, or organizations imply endorsement by the US Government.

Received for publication October 16, 2003, and accepted in revised form March 16, 2004.

Address correspondence to: Sivasubramanian Baskar, Building 567, Room 203, National Cancer Institute at Frederick, Frederick, Maryland 21702, USA. Phone: (301) 846-5147; Fax: (301) 8466107; E-mail: baskar@ncifcrf.gov.
1. Boon, T., Cerottini, J.C., Van den Eynde, B., van der Bruggen, P., and Van Pel, A. 1994. Tumor antigens recognized by T lymphocytes. Annu. Rev. Immunol. 12:337-365.

2. Wang, R.F., and Rosenberg, S.A. 1999. Human tumor antigens for cancer vaccine development. Immunol. Rev. 170:85-100.

3. Van Der Bruggen, P., et al. 2002. Tumor-specific shared antigenic peptides recognized by human $\mathrm{T}$ cells. Immunol. Rev. 188:51-64.

4. Levy, R., Warnke, R., Dorfman, R.F., and Haimovich, J. 1977. The monoclonality of human B-cell lymphomas. J. Exp. Med. 145:1014-1028.

5. Stevenson, G.T., Elliott, E.V., and Stevenson, F.K. 1977. Idiotypic determinants on the surface immunoglobulin of neoplastic lymphocytes: a therapeutic target. Fed. Proc. 36:2268-2271.

6. Lynch, R.G., Graff, R.J., Sirisinha, S., Simms, E.S., and Eisen, H.N. 1972. Myeloma proteins as tumorspecific transplantation antigens. Proc. Natl. Acad. Sci. U. S. A. 69:1540-1544.

7. Sanz, I. 1991. Multiple mechanisms participate in the generation of diversity of human $\mathrm{H}$ chain CDR3 regions. J. Immunol. 147:1720-1729.

8. Bakkus, M.H., Heirman, C., Van Riet, I., Van Camp, B., and Thielemans, K. 1992. Evidence that multiple myeloma Ig heavy chain VDJ genes contain somatic mutations but show no intraclonal variation. Blood. 80:2326-2335.

9. Stevenson, F.K., et al. 1998. Insight into the origin and clonal history of B-cell tumors as revealed by analysis of immunoglobulin variable region genes. Immunol. Rev. 162:247-259.

10. Kosmas, C., et al. 1999. Molecular analysis of immunoglobulin genes in multiple myeloma. Leuk. Lymphoma. 33:253-265.

11. Wilson, P.C., et al. 1998. Somatic hypermutation introduces insertions and deletions into immunoglobulin V genes. J. Exp. Med. 187:59-70.

12. Kuppers, R. 2003. Somatic hypermutation and B cell receptor selection in normal and transformed human B cells. Ann. N. Y. Acad. Sci. 987:173-179.

13. Kwak, L.W., et al. 1992. Induction of immune responses in patients with B-cell lymphoma against the surface-immunoglobulin idiotype expressed by their tumors. N. Engl.J. Med. 327:1209-1215.

14. Yi, Q., and Osterborg, A. 1996. Idiotype-specific T cells in multiple myeloma: targets for an immunotherapeutic intervention? Med. Oncol. 13:1-7.

15. Nelson, E.L., et al. 1996. Tumor-specific, cytotoxic
T-lymphocyte response after idiotype vaccination for B-cell, non-Hodgkin's lymphoma. Blood. 88:580-589.

16. Osterborg, A., et al. 1998. Idiotype immunization combined with granulocyte-macrophage colonystimulating factor in myeloma patients induced type I, major histocompatibility complex-restricted, CD8- and CD4-specific T-cell responses. Blood. 91:2459-2466.

17. Bendandi, M., et al. 1999. Complete molecular remissions induced by patient-specific vaccination plus granulocyte-monocyte colony-stimulating factor against lymphoma. Nat. Med. 5:1171-1177.

18. Titzer, S., et al. 2000. Vaccination of multiple myeloma patients with idiotype-pulsed dendritic cells: immunological and clinical aspects. Br.J. Haematol. 108:805-816.

19. Wen, Y.J., and Lim, S.H. 1997. T cells recognize the $\mathrm{VH}$ complementarity-determining region 3 of the idiotype protein of B cell non-Hodgkin's lymphoma. Eur. J. Immunol. 27:1043-1047.

20. Wen, Y.J., Ling, M., and Lim, S.H. 1998. Immunogenicity and cross-reactivity with idiotypic IgA of VH CDR3 peptide in multiple myeloma. Br. J. Haematol. 100:464-468.

21. Wen, Y.J., and Lim, S.H. 1999. Different properties of T-cell epitopes within complementarity-determining regions 1 and 2 of idiotypic $\mathrm{VH}$ in B-lymphoma. Scand. J. Immunol. 50:296-301.

22. Fagerberg, J., et al. 1999. T-cell-epitope mapping of the idiotypic monoclonal IgG heavy and light chains in multiple myeloma. Int. J. Cancer. 80:671-680.

23. Rezvany, M.R., et al. 2000. Autologous T lymphocytes recognize the tumour-derived immunoglobulin VH-CDR3 region in patients with B-cell chronic lymphocytic leukaemia. Br. J. Haematol. 111:230-238.

24. Hansson, L., Rabbani, H., Fagerberg, J., Osterborg, A., and Mellstedt, H. 2003. T-cell epitopes within the complementarity-determining and framework regions of the tumor-derived immunoglobulin heavy chain in multiple myeloma. Blood. 101:4930-4936.

25. Trojan, A., et al. 2000. Immunoglobulin framework-derived peptides function as cytotoxic T-cell epitopes commonly expressed in B-cell malignancies. Nat. Med. 6:667-672.

26. Harig, S., et al. 2001. Induction of cytotoxic T-cell responses against immunoglobulin $\mathrm{V}$ region- derived peptides modified at human leukocyte antigen-A2 binding residues. Blood. 98:2999-3005.

27. Gricks, C.S., Rawlings, E., Foroni, L., Madrigal, J.A., and Amlot, P.L. 2001. Somatically mutated regions of immunoglobulin on human B-cell lymphomas code for peptides that bind to autologous major histocompatibility complex class I, providing a potential target for cytotoxic T cells. Cancer Res. 61:5145-5152.

28. Baskar, S., Parronchi, P., Mohapatra, S., Romagnani, S., and Ansari, A.A. 1992. Human T cell responses to purified pollen allergens of the grass, Lolium perenne. Analysis of relationship between structural homology and $\mathrm{T}$ cell recognition. J. Immunol. 148:2378-2383.

29. Kobrin, C.B., and Kwak, L.W. 1997. Development of vaccine strategies for the treatment of B-cell malignancies. Cancer Invest. 15:577-587.

30. Parker, K.C., Bednarek, M.A., and Coligan, J.E. 1994. Scheme for ranking potential HLA-A2 binding peptides based on independent binding of individual peptide side-chains. J. Immunol. 152:163-175.

31. Rammensee, H., Bachmann, J., Emmerich, N.P., Bachor, O.A., and Stevanovic, S. 1999. SYFPEITHI: database for MHC ligands and peptide motifs. Immunogenetics. 50:213-219.

32. Gulukota, K., Sidney, J., Sette, A., and DeLisi, C. 1997. Two complementary methods for predicting peptides binding major histocompatibility complex molecules. J. Mol. Biol. 267:1258-1267.

33. Topalian, S.L., et al. 1994. Melanoma-specific CD4+ T lymphocytes recognize human melanoma antigens processed and presented by Epstein-Barr virus-transformed B cells. Int. J. Cancer. 58:69-79.

34. Jung, T., Schauer, U., Heusser, C., Neumann, C., and Rieger, C. 1993. Detection of intracellular cytokine by flow cytometry. J. Immunol. Methods. 159:197-207.

35. Germain, R.N., and Margulies, D.H. 1993. The biochemistry and cell biology of antigen processing and presentation. Annu. Rev. Immunol. 11:403-450.

36. Michael, A., and Pandha, H.S. 2003. Renal-cell carcinoma: tumour markers, T-cell epitopes, and potential for new therapies. Lancet Oncol. 4:215-223

37. Finn, O.J., et al. 1995. MUC-1 epithelial tumor mucin-based immunity and cancer vaccines. Immunol. Rev. 145:61-89. 
38. Osterborg, A., et al. 1995. Idiotype-specific T cells in multiple myeloma stage I: an evaluation by four different functional tests. Br. J. Haematol. 89:110-116.

39. Wen, Y.J., Barlogie, B., and Yi, Q. 2001. Idiotype-specific cytotoxic T lymphocytes in multiple myeloma: evidence for their capacity to lyse autologous primary tumor cells. Blood. 97:1750-1755.

40. Dutoit, V., et al. 2001. Heterogeneous T-cell response to MAGE-A10 (254-262): high avidity-specific cytolytic T lymphocytes show superior antitumor activity. Cancer Res. 61:5850-5856.

41. Heiser, A., et al. 2001. Human dendritic cells transfected with renal tumor RNA stimulate polyclonal $\mathrm{T}$-cell responses against antigens expressed by primary and metastatic tumors. Cancer Res. 61:3388-3393.
42. Valmori, D., et al. 2002. Vaccination with a MelanA peptide selects an oligoclonal $\mathrm{T}$ cell population with increased functional avidity and tumor reactivity. J. Immunol. 168:4231-4240.

43. Pardoll, D.M., and Topalian, S.L. 1998. The role of CD4+ T cell responses in anti-tumor immunity. Curr. Opin. Immunol. 10:588-594.

44. Yanagawa, H., et al. 1999. Presence and potent immunosuppressive role of interleukin-10 in malignant pleural effusion due to lung cancer. Cancer Lett. 136:27-32.

45. Sheu, B.C., et al. 2001. Predominant Th2/Tc2 polarity of tumor-infiltrating lymphocytes in human cervical cancer. J. Immunol. 167:2972-2978.

46. Jones, E.A., Pringle, J.H., Angel, C.A., and Rees, R.C. 2002. Th1/Th2 cytokine expression and its relationship with tumor growth in B cell non-
Hodgkin's lymphoma (NHL). Leuk. Lymphoma. 43:1313-1321.

47. Kammula, U.S., et al. 1999. Functional analysis of antigen-specific T lymphocytes by serial measurement of gene expression in peripheral blood mononuclear cells and tumor specimens. J. Immunol. 163:6867-6875.

48. Zhu, D., et al. 2002. Acquisition of potential N-glycosylation sites in the immunoglobulin variable region by somatic mutation is a distinctive feature of follicular lymphoma. Blood. 99:2562-2568.

49. Kabat, E.A., Wu, T.T., Perry, H.M., Gottesman, K.S., and Foeller, C. 1991. Sequences of proteins of immunological interest. U.S. Department of Health and Human Services, Public Health Service, National Institutes of Health. Washington, D.C., USA. NIH publication 91-3242. 